\title{
A new perspective of the climatological features of upper-level cut-off lows in the Southern Hemisphere
}

Article

Published Version

Creative Commons: Attribution 4.0 (CC-BY)

Open Access

Pinheiro, H. R., Hodges, K. I., Gan, M. A. and Ferreira, N. J. (2017) A new perspective of the climatological features of upper-level cut-off lows in the Southern Hemisphere. Climate Dynamics, 48 (1). pp. 541-559. ISSN 0930-7575 doi: https://doi.org/10.1007/s00382-016-3093-8 Available at https://centaur.reading.ac.uk/65775/

It is advisable to refer to the publisher's version if you intend to cite from the work. See Guidance on citing.

Published version at: http://link.springer.com/article/10.1007/s00382-016-3093-8/fulltext.html

To link to this article DOI: http://dx.doi.org/10.1007/s00382-016-3093-8

Publisher: Springer

All outputs in CentAUR are protected by Intellectual Property Rights law, including copyright law. Copyright and IPR is retained by the creators or other copyright holders. Terms and conditions for use of this material are defined in the End User Agreement.

www.reading.ac.uk/centaur 
Central Archive at the University of Reading

Reading's research outputs online 


\title{
A new perspective of the climatological features of upper-level cut-off lows in the Southern Hemisphere
}

\author{
Henri Rossi Pinheiro ${ }^{1}$ Kevin Ivan Hodges ${ }^{2} \cdot$ Manoel Alonso Gan $^{1} \cdot$ \\ Nelson Jesuz Ferreira ${ }^{1}$
}

Received: 16 November 2015 / Accepted: 18 March 2016

(C) The Author(s) 2016. This article is published with open access at Springerlink.com

\begin{abstract}
This study presents a detailed view of the seasonal variability of upper-level cut-off lows (COLs) in the Southern Hemisphere. The COLs are identified and tracked using data from a 36-year period of the European Centre for Medium Range Weather Forecast reanalysis (ERAInterim). The objective identification of the COLs uses a new approach, which is based on $300 \mathrm{hPa}$ relative vorticity minima, and three restrictive criteria of the presence of a cold-core, stratospheric potential vorticity intrusion, and cut-off cyclonic circulation. The highest COL activity is in agreement with previous studies, located near three main continental areas (Australia, South America, and Africa), with maximum frequencies usually observed in the austral autumn. The COL mean intensity values show a marked seasonal and spatial variation, with maximum (minimum) values during the austral winter (summer), a unique feature that has not been observed previously in studies based on the geopotential. The link between intensity and lysis is examined, and finds that weaker systems are more susceptible to lysis in the vicinity of the Andes Cordillera, associated with the topographic Rossby wave. Lysis and genesis regions are close to each other, confirming that COLs are quasi-stationary systems. Also, COLs tend to move eastward and are faster over the higher latitudes. The mean growth/decay rates coincide with the major genesis and lysis density regions, such as the significant decay values
\end{abstract}

Henri Rossi Pinheiro

henri.pinheiro@cptec.inpe.br

1 Center for Weather Forecast and Climate Studies, National Institute for Space Research, Sao Jose dos Campos, SP, Brazil

2 Department of Meteorology, The University of Reading, Reading, UK across the Andes all year. As a consequence of using vorticity for the tracking method a longer lifetime of COLs is detected than in other studies, but this does not affect the total frequency of occurrence. Comparisons with other studies suggest that the differences in seasonality are due to uncertainties in the reanalyses and the methods used to identify COLs.

Keywords Cut-off lows · Climatology $\cdot$ Southern hemisphere $\cdot$ Variability

\section{Introduction}

Cut-off Low pressure systems (COLs) are defined as coldcore lows in the middle and upper troposphere that form after their detachment from the mid-latitude westerlies (Palmén and Newton 1969). COLs develop from a preexisting cold trough in the upper air flow and move toward the equatorward side of the jet stream, leaving an isolated cold cyclonic vortex. The intensity of COLs associated with their cyclonic circulation is usually highest at upper levels but decreases toward the Earth's surface. They may remain confined at upper levels or deepen downward resulting in surface cyclogenesis (Miky Funatsu et al. 2004). COLs usually move slowly and preferably eastward, but may remain stationary or move westward, i.e., retrogressive motion. A common COL feature is their relatively short lifetime with the majority of events lasting no more than 3 days (Price and Vaughan 1992).

COLs often affect surface weather conditions via their associated rainfall, for example, they have caused heavy rainfall and floods in South Africa (Taljaard 1985; Singleton and Reason 2006) and snowfall in the Andean highland region (Vuille and Ammann 1997). COLs also play an 
important role in the mass flux between the stratrosphere and troposphere (Holton et al. 1995). The process of COL genesis is accompanied by tropopause folding and the isentropic advection of stratrospheric air from the extratropics, leading to conditions of anomalous values of Potential Vorticity (PV) and static stability in the subtropical troposphere (Davies and Schuepbach 1994; Ancellet et al. 1994; Van Delden and Neggers 2003). This stratrosphere-troposphere exchange affects the ozone concentration in the lower troposphere and allows PV to be used as a useful quantity for tracking COLs (Hernández 1999; Cuevas and Rodríguez 2002; Wernli and Sprenger 2007). Several other dynamical features of COLs, such as Rossby wave breaking have been broadly documented by Hoskins et al. (1985) and Ndarana and Waugh (2010, hereafter NW10).

Several hypotheses have been proposed to explain the seasonal variability of COLs. Kentarchos and Davies (1998) identified COLs in the Northern Hemisphere based on the $200 \mathrm{hPa}$ geopotential height. They observed the highest frequency during summer, and associated it with the general decrease of upper level westerlies, as suggested earlier by Price and Vaughan (1992). Other mechanisms may also be important for the seasonality of COLs. The role of diabatic process for the decay stage of COLs has been emphasized by Garreaud and Fuenzalida (2007). During the austral summer, deep moist convection is most effective inland over subtropical latitudes over South America and Africa. The latent heat release associated with the cumulus convection in the $\mathrm{COL}$ core tends to decrease the horizontal temperature gradient across the system, reducing the frequency and/or lifetime of COLs (Kousky and Gan 1981; Hoskins et al. 1985). Unlike the situation in other continental areas in the Southern Hemisphere (SH), it is reasonably dry over most of Australia and therefore the latent heating effect is insignificant. Satyamurty and Seluchi (2007) pointed out that in the absence of the strong release of latent heating in the mid-troposphere the adiabatic cooling due to vertical motion and radiative processes may contribute to intensify the cold core.

Early observational studies of COLs (Price and Vaughan 1992; Kentarchos and Davies 1998; among others) were based on subjective analyses, so that longer period climatologies required exhaustive analysis. More recently, automated methods (e.g. Nieto et al. 2005) have allowed the analysis to be extended to longer periods and larger areas. In the SH, the first climatological study of COLs based on an objective analysis was carried out by Fuenzalida et al. (2005, hereafter F05). In fact, they use a methodology that combines objective detection with visual inspection for a 31-year period. Initially, COLs were identified based on an objective analysis using the laplacian of the geopotential field at $500 \mathrm{hPa}$ after which they were validated subjectively (cold core and cut-off). F05 showed that the highest occurrence of COLs in the SH is around continental areas, preferentially in Australia and New Zealand, the west coast of South America, and southern Africa. Later, climatological studies of COLs in the SH were performed focusing on particular regions (Campetella and Possia 2007, for South America; Singleton and Reason 2007, hereafter SR07, for South Africa) or for the entire SH (Reboita et al. 2010, hereafter R10; NW10; Favre et al. 2012, hereafter F12), using the geopotential field for the tracking.

Whilst previous studies agree in many aspects of COLs such as their spatial distribution and the mean life time, there are significant differences in terms of seasonality and number of COLs, which seem to be related to the reanalyses data used and the method used to identify COLs. Differences in how observations are assimilated by the reanalysis can lead to uncertainties in the results, this is most obvious for comparisons involving the older reanalyses, as shown in R10 and discussed in Sect. 3.2. In addition, the method used to identify COLs also affects the seasonality and frequency of COLs as each scheme imposes different conditions and thresholds for the COL identification. Therefore, it is possible to say that statistics of COLs can only be assessed by comparing with each study as there is no "truth" to be compared with.

Unlike previous approaches, the current study uses the relative vorticity field to identify COLs. The choice of relative vorticity for the tracking is due to the fact that the magnitude of vorticity associated with the COLs does not depend on the latitude, whereas the geopotential gradient is normally weak at lower latitudes. Therefore, the use of vorticity allows the identification of COLs in a weak geopotential gradient, which is the case of most COLs at relatively low latitudes, such as those northward from $30^{\circ} \mathrm{S}$. Moreover, another advantage of using vorticity, shown in this study, is that this variable highlights the spatial and seasonal variation of COL mean intensity. This study also emphasizes aspects that have not previously been investigated, such as genesis and lysis as well as the growth/ decay rate, and how these are related to the mean intensity of COLs. The study is based on a more recent re-analysis product than used in previous studies of COLs in the SH.

To improve the understanding of COLs this study presents a hemispheric climatology of subtropical COLs using an objective method based on the relative vorticity at $300 \mathrm{hPa}$ and their main physical characteristics, such as temperature and $\mathrm{PV}$. Also, comparing the COL frequency in this study with earlier studies, we will attempt to verify whether the differences among them are related to the method or dataset used.

The paper continues with details of the data, tracking algorithm, criteria for the COL identification and outputs of the algorithm in Sect. 2. The results are presented in Sect. 3. Section 4 summarizes the results and presents the conclusions. 


\section{Data and methodology}

\subsection{Data}

The climatology of COLs has been obtained for a 36-year period (1979-2014) using data from the European Centre for Medium-Range Weather Forecast (ECMWF)-Interim reanalysis (hereafter ERA-I). This is a more modern reanalysis than used in previous studies of COLs at $300 \mathrm{hPa}$ in the SH. ERA-I uses a spectral model with resolution of TL255 and 60 vertical hybrid levels (Simmons et al. 2007). The data used here in on the reduced resolution $1.5^{\circ} \times 1.5^{\circ}$ grid, which is suitable to identify synoptic systems. Similar to previous studies of extra-tropical cyclones using vorticity (Hoskins and Hodges 2002, 2005) the data are truncated at total wavenumber 42 (referred to herein as T42), and the large scale background for total wavenumbers $\leq 5$ are removed.

The full set of variables used for COL tracking and identification are the relative vorticity, air temperature, potential vorticity and zonal wind at $300 \mathrm{hPa}$, obtained at 6 hourly time resolution. The $300 \mathrm{hPa}$ pressure level was used because COLs usually reach their maximum intensity just below the dynamical tropopause, which is around $300 \mathrm{hPa}$ in the subtropical latitudes. This choice is in agreement with R10 who showed that larger frequencies of COLs are found at $300 \mathrm{hPa}$ compared to 500 and $200 \mathrm{hPa}$.

\subsection{New criteria for the COL Tracking}

In this study the identification and tracking of COLs was performed objectively, through a modified version of TRACK (Hodges 1994, 1995, 1999). Initially all vorticity centers are tracked. Because the method does not differentiate between closed circulations and troughs in the high levels, additional criteria were included in this study to correctly identify COLs.

The criteria used to detect COLs in this study are based on well-known COL physical characteristics through the following steps: (1) tracking the Minima of Cyclonic Relative Vorticity (MCRV); (2) temperature filter; (3) potential vorticity filter; and (4) identification of easterly flow southward of the MCRV. The steps (2) and (3) were applied in order to select only upper tropospheric cold cyclonic vortices with stratospheric air origin. The search for cold-cores and the high cyclonic PV in steps (2) and (3) are applied over a spherical cap region within a 5.0 degree geodesic radius around the MCRV and not for neighbouring grid points as was used in previous studies (e.g. R10; NW10). The problem in considering neighboring points is that the vorticity minima may offset from the geopotential. The latter additional step (4) is designed to guarantee the full detachment of COL centers from the high level westerly flow. All these criteria were applied at the $300 \mathrm{hPa}$ isobaric level.

Initially (step 1), the tracking is performed using a threshold $-1.0 \times 10^{-5} \mathrm{~s}^{-1}$. The maximum displacement distance in a time step is set at 6 geodesic degrees for the tracking. There is no restriction for the minimum lifetime displacement distance as COLs are semi-stationary systems. Previous studies have used the geopotential to track COLs (Campetella and Possia 2007, hereafter CP07; $\mathrm{R} 10$ ), however there are drawbacks in using the geopotential which has generally weak gradients at lower latitudes whereas the vorticity variation along a streamline is appreciable because the base of the trough represents the relative vorticity minimum in the $\mathrm{SH}$, even at low latitudes. The method has also been applied to the tracking of COLs at $300 \mathrm{hPa}$ using geopotential minima, this confirms that the track density presents lower values over low latitudes than observed in the relative vorticity field, as discussed in Sect. 3.2.

In step 2 a search for a temperature minimum is performed over a spherical cap region within a $5.0^{\circ}$ geodesic radius from the MCRV. The temperature minimum is determined after first removing the zonal mean from the temperature data for each time step, i.e., the difference between grid points and the zonal mean temperature. Tracks with at least four consecutive points ( 1 day) with a temperature minimum less than or equal to $-3^{\circ}$ Kelvin are retained for the next step. This threshold is chosen in a somewhat arbitrary way where several sensitivity tests have been performed with different values. This constraint ensures the identification of only cold core vortices.

Previous studies have used different methods to determine the cold-core condition. For the COLs at $300 \mathrm{hPa}$, $\mathrm{R} 10$ computed the difference in temperature between 300 and $400 \mathrm{hPa}$, and retained those candidate COLs where the grid point east from the geopotential minimum has higher values of temperature. Similarly, NW10 used the thickness field of $250-500 \mathrm{hPa}$ for COLs at $250 \mathrm{hPa}$ and compared the value in the geopotential minimum with the value in its surroundings. Different from other studies, the method presented here performs the search of the cold-core using the temperature in $300 \mathrm{hPa}$ but the average temperature of $300-500 \mathrm{hPa}$ has also been tested. As it found no significant differences in terms of number of COLs, the temperature at $300 \mathrm{hPa}$ was used.

In the following step (step 3) a similar criterion is applied for the PV field, i.e., a search for a PV minimum is performed over a spherical cap region within a 5.0 degrees geodesic radius from the MCRV. The PV minimum is computed by first removing the zonal mean from the PV data for each time step. All the tracks that have at 
least four consecutive points with PV minima values less than or equal to -2 PVU (1 PVU $=10^{-6} \mathrm{~m}^{2} \mathrm{~s}^{-1} \mathrm{~K} \mathrm{~kg}^{-1}$ ) are stored and used for further processing. Several studies have investigated COLs from a PV perspective (e.g. Bell and Keyser 1993; Bell and Bosart 1993; Van Delden and Neggers 2003) and have highlighted that the genesis of COLs is manifested by a detachment of an isolated PV anomaly from its stratospheric air reservoir. In this study the constraint imposed on the PV ensures that only the tracks associated with relatively large negative PV anomalies in their life cycle are retained. Lastly (step 4), to satisfy the full conditions of a COL the zonal wind is analyzed. The zonal wind at five degrees south from the MCRV must be negative (less than or equal to $-8 \mathrm{~m} / \mathrm{s}$ ) for at least four points along the track. This condition is required to consider only cold-core systems detached from the westerlies. To be included in the statistical analysis, COLs are required to last at least $24 \mathrm{~h}$ (four consecutive time steps), to eliminate those tracks with very short life cycle.

After the identification steps are completed, the selection of subtropical COLs was performed by selecting only those tracks that move northward and reach at least $40^{\circ} \mathrm{S}$ or have their genesis north of $40^{\circ} \mathrm{S}$. These criteria are necessary to avoid the identification of mid-latitude COLs and to guarantee that the cold core is completely detached from the source region. The northern boundary is fixed at $15^{\circ} \mathrm{S}$, so tracks northward of $15^{\circ} \mathrm{S}$ are excluded. The more northerly latitudes were rejected in order to avoid the small probability of the occurrence of tropical cold core cyclonic vortices (Kousky and Gan 1981), which have dynamical mechanisms different from subtropical COLs (Mishra et al. 2001). The algorithm was evaluated by a visual inspection of the $300 \mathrm{hPa}$ streamline and geopotential fields for a 1-year period. The area chosen for validation of the methodology was South America and its surrounding areas $\left(100^{\circ} \mathrm{W}-20^{\circ} \mathrm{W}\right.$ and $\left.50^{\circ} \mathrm{S}-15^{\circ} \mathrm{S}\right)$, which includes a region of significant density and large seasonal variability of COLs (F05, R10). The accuracy of the described method for the regional area was found to be around $90 \%$ compared to the visual analysis.

Spatial statistics are created from the tracks using the spherical kernel estimators (Hodges 1996) for the austral seasons of autumn (March-May), winter (JuneAugust), spring (September-November), and summer (December-February).

\section{Results}

This section initially presents the seasonal characteristics of the COLs in the SH followed by comparisons with previous studies.

\subsection{Temporal and spatial distribution of COL activity}

Several aspects of the COL activity at $300 \mathrm{hPa}$ in the $\mathrm{SH}$ are shown in Figs. 1, 2, 3, 4, 5, 6, 7, 8, 9, 10, 11 and 12. During the 36-year period (1979-2014) the tracking algorithm identified 10,248 COLs in the study region, with an annual average of 285 cases. The track density (Fig. 1) shows a zonally asymmetric pattern in the subtropical latitudes. The density maxima are located around the continents and minima over the oceans, although there are large track density values in the western Pacific. The highest density of COLs occurs over eastern Australia and New Zealand, generally greater than 16 events per season per unit area ( $5^{\circ}$ spherical cap $\cong 10^{6} \mathrm{Km}^{2}$ ). The large number of COLs in the latter region may be associated with the decrease in the westerlies (Kentarchos and Davies 1998) and the frequent occurrence of blocking (Trenberth and Mo 1985; Marques and Rao 2000). In the present study, a pronounced seasonal cycle of COLs is found, with a peak in the austral autumn with an average of $30.8 \%$ of the yearly track numbers followed by summer (27.5\%), spring $(22.5 \%)$, and winter $(19.2 \%)$. The main belt of COL activity shifts about $5^{\circ}$ towards the equator from summer to winter, following the meridional displacement of the polar and subtropical jet stream. This displacement equatorward from winter to summer is in agreement with F12, who identified COLs at $500 \mathrm{hPa}$ using data from the NCEP-DOE II reanalysis data (Kanamitsu et al. 2002).

Another measure of the distribution of COLs is the feature density which is computed using all points along the tracks rather than choosing the closest track points to the estimation points as with the track density (Hodges 1996). However the feature density is more sensitive to the presence of slow moving systems, i.e., those that move slower contribute more to the feature density (Hoskins and Hodges 2002) in particular regions. Figure 2 shows that the main regions of high feature density occur around the three main continental areas most of the year, however in summer the activity extends across the central Indian Ocean, from the eastern Pacific Ocean to South America, and there is also a maximum from north of New Zealand to the western Pacific. The behavior of the feature density is usually dominated by bull's-eyes associated with slow moving systems (Hoskins and Hodges 2002), which can frequently be seen in the summer eastern subtropical Pacific. Irrespective of season, a maximum in feature density is found immediately west of the subtropical coast of Chile and a minimum on the lee side of the Andes Cordillera, a feature that has already been pointed out by Pizarro and Montecinos (2000). Over the mainland, a secondary maximum appears in southern Brazil as found by $\mathrm{CP} 07$, in particular in autumn. 


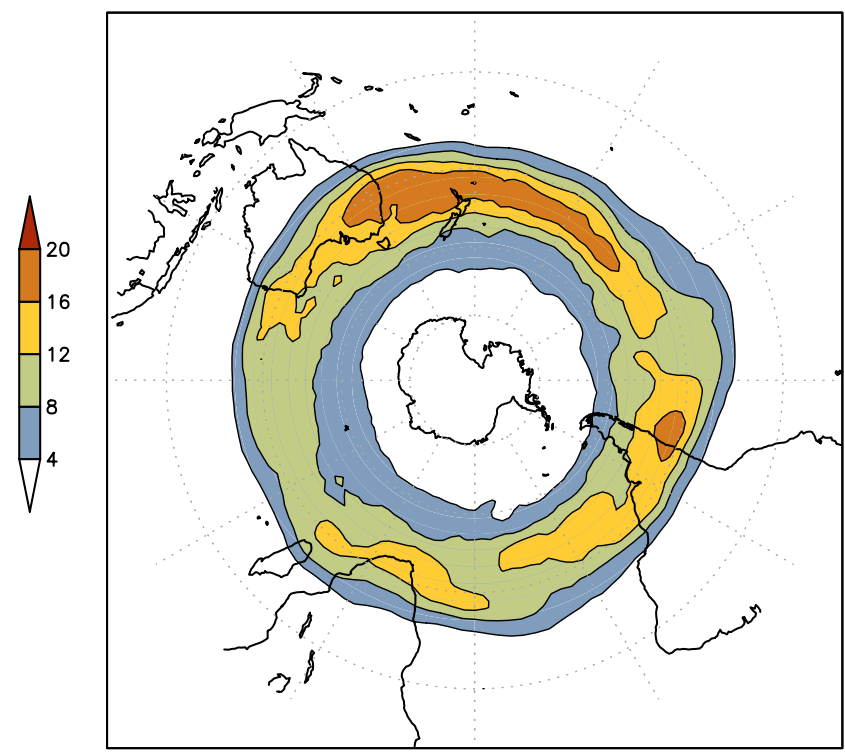

(a) Autumn

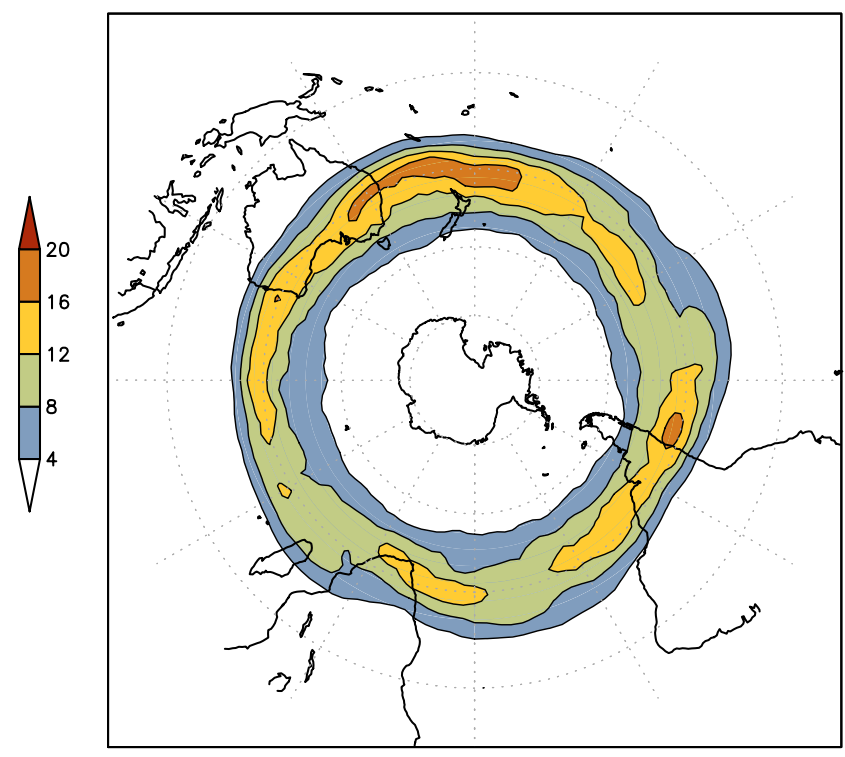

(c) Spring

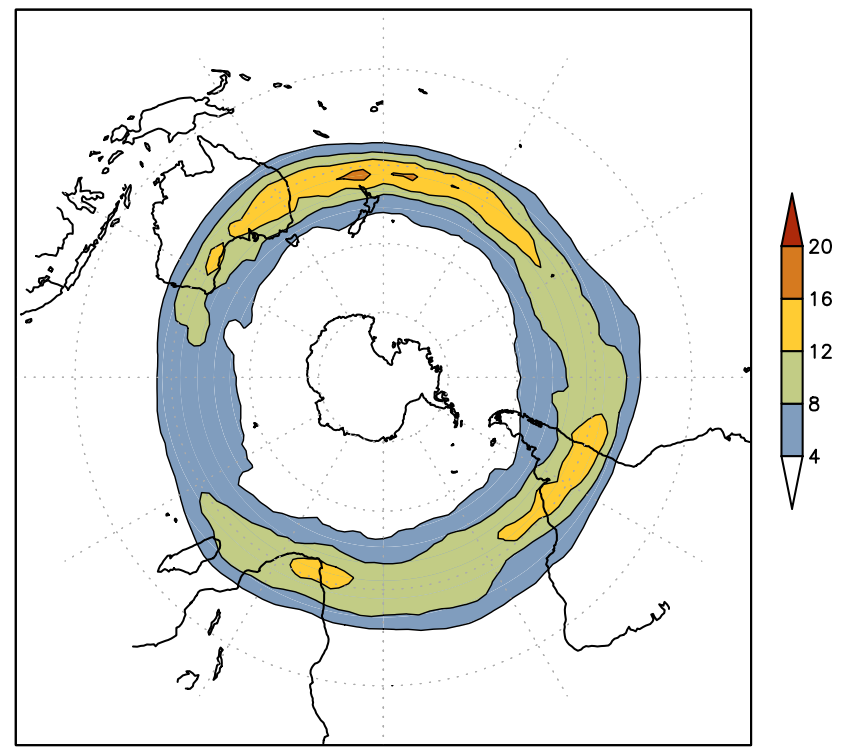

(b) Winter

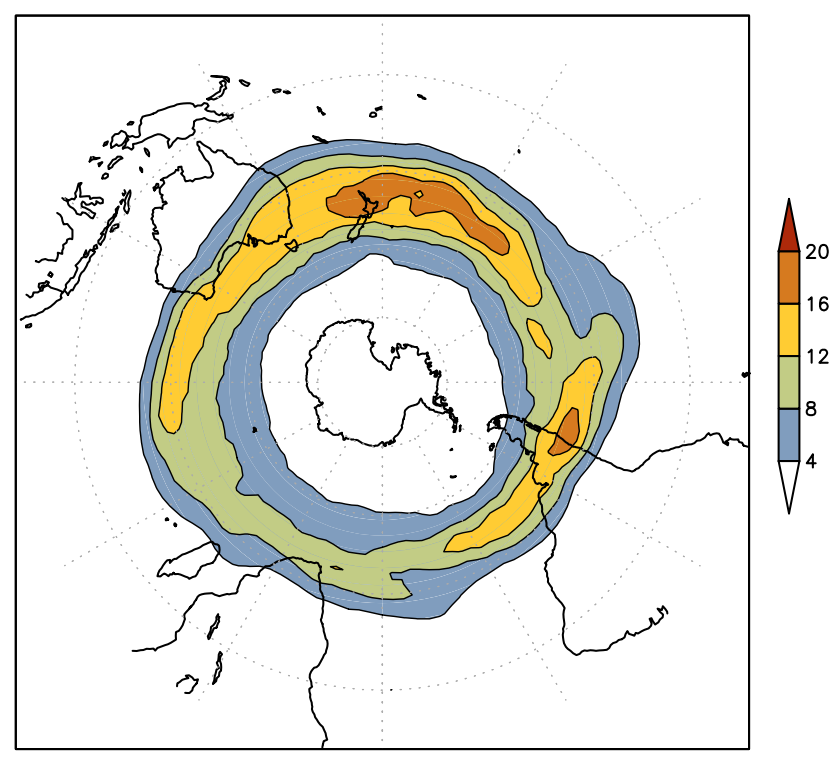

(d) Summer

Fig. 1 Seasonal Southern Hemisphere COL track density for the austral seasons: a autumn (MAM), b winter (JJA), c spring (SON), and d summer (DJF), for the period from 1979 to 2014 . Unit: number per unit area per season, the unit area is equivalent to a $5^{\circ}$ spherical cap $\left(\sim 10^{6} \mathrm{~km}{ }^{2}\right)$

According to Figs. 1 and 2, most COLs are located in continental neighborhoods, thus the monthly distribution of COLs is analyzed in three different sectors, defined as follows: $20^{\circ} \mathrm{W}-80^{\circ} \mathrm{E}$ for Africa, $80^{\circ} \mathrm{E}-140^{\circ} \mathrm{W}$ for Australia, and $140^{\circ} \mathrm{W}-20^{\circ} \mathrm{W}$ for South America. These domains are defined based on the maxima track density located around the continents. Figure 3 shows the monthly distribution for these three sectors expressed as a percentage of the total annual number of COLs for each region. This shows that there is a well-defined cycle with the monthly distributions appearing quite similar for the three sectors, with a maximum in March, followed by a decrease to a minimum in August-September. For the Australia sector, a secondary maximum is observed in December, preceded by a rapid increase in frequency from August. These results are partially in agreement with F05 for COLs identified at the $500 \mathrm{hPa}$ level. They observed a monthly distribution similar to our study for the South America sector, with a maximum in April but the minimum occurring in February. The differences in seasonality of COLs between 500 and $300 \mathrm{hPa}$ 


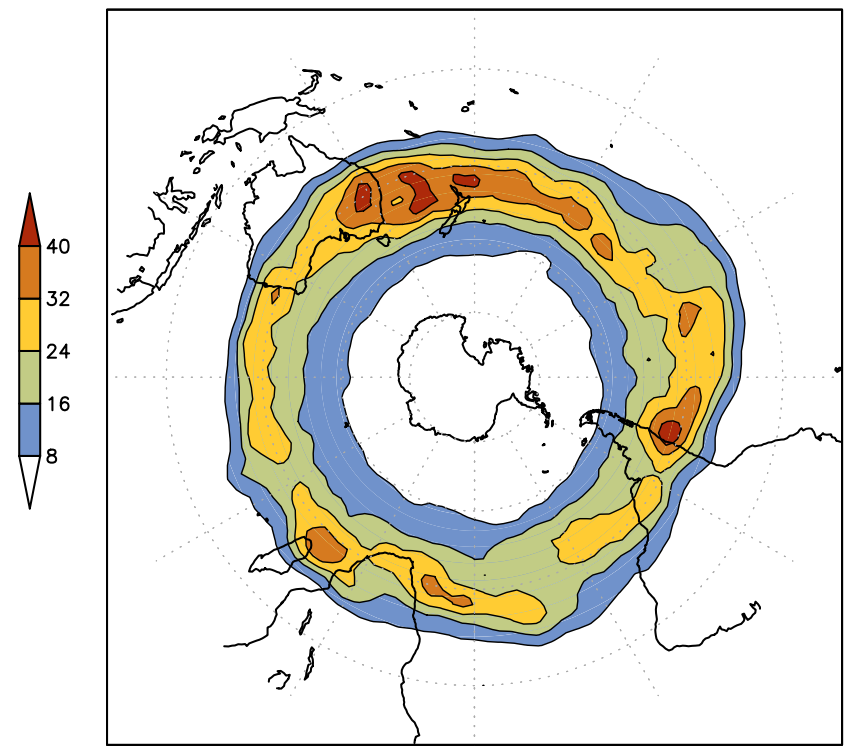

(a) Autumn

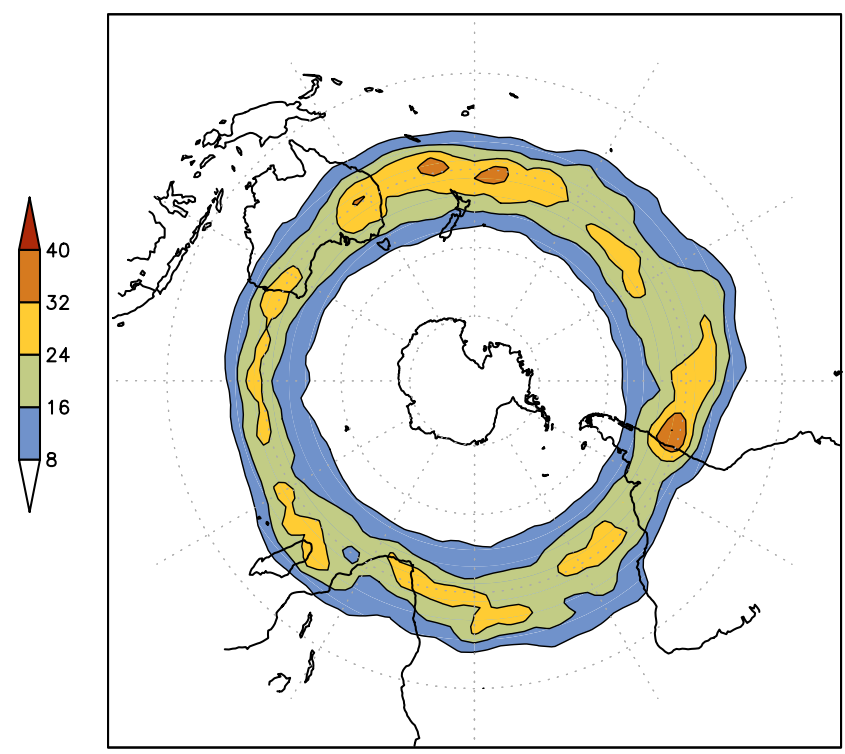

(c) Spring

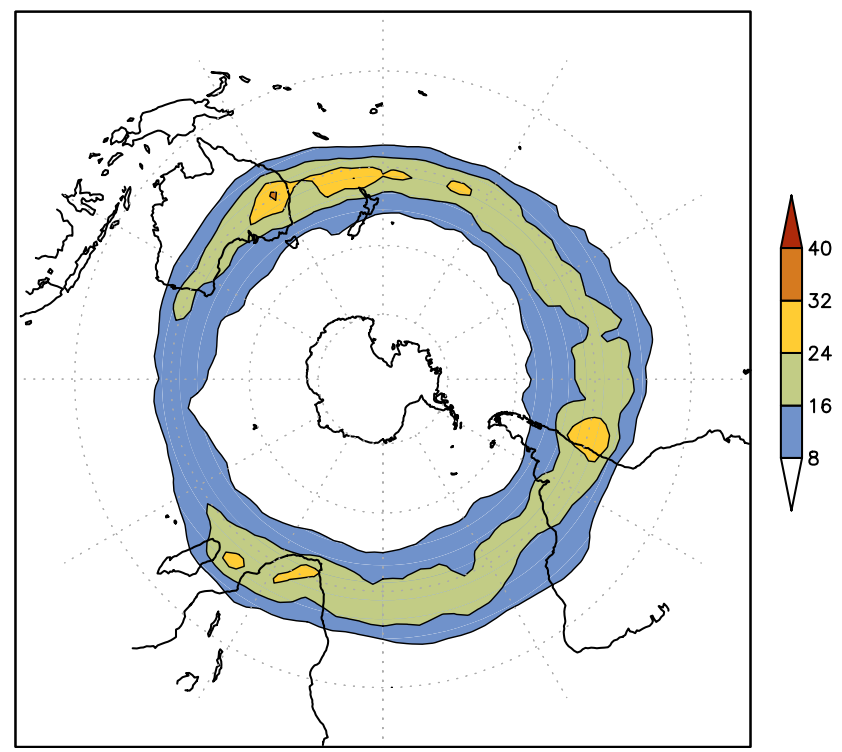

(b) Winter

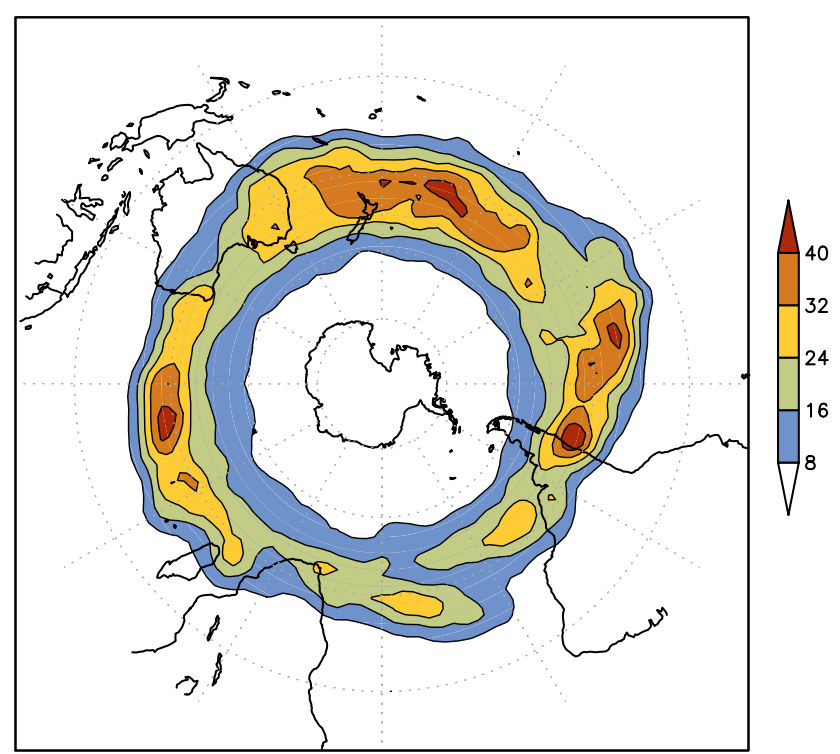

(d) Summer

Fig. 2 Seasonal Southern Hemisphere COL feature density for the austral seasons: a autumn (MAM), b winter (JJA), c spring (SON), and d summer (DJF), for the period from 1979 to 2014. Unit: number

is more related to the pressure level used and not to the detection method, as observed in R10.

For the African sector, F05 found the maximum (minimum) in winter (summer), while the Australian sector shows a distribution almost constant during the year. Considering the whole $\mathrm{SH}$ (Fig. 3), our results are much more consistent with the climatology of NW10 for COLs identified at the $250 \mathrm{hPa}$ level, with the maximum occurring in March-April, and the minimum in August-September. The annual cycle of COL occurrence in terms of decadal

per unit area per season, the unit area is equivalent to a $5^{\circ}$ spherical cap $\left(\sim 10^{6} \mathrm{~km}^{2}\right)$

time scale (figure not shown) exhibits the same shape as the whole period but with an increasing trend in the number of COLs observed from the period 1979-1988 to the period 1989-2008, as shown in F12. Most of the months show an increase in the number of COLs, the largest value occurs in April (6.7 events per month), while December has a decrease of 0.7 events per month.

During the study period (1979-2014), COLs exhibit a strong interannual variability (Fig. 4), with the largest standard deviation in South America (11.5), followed by 


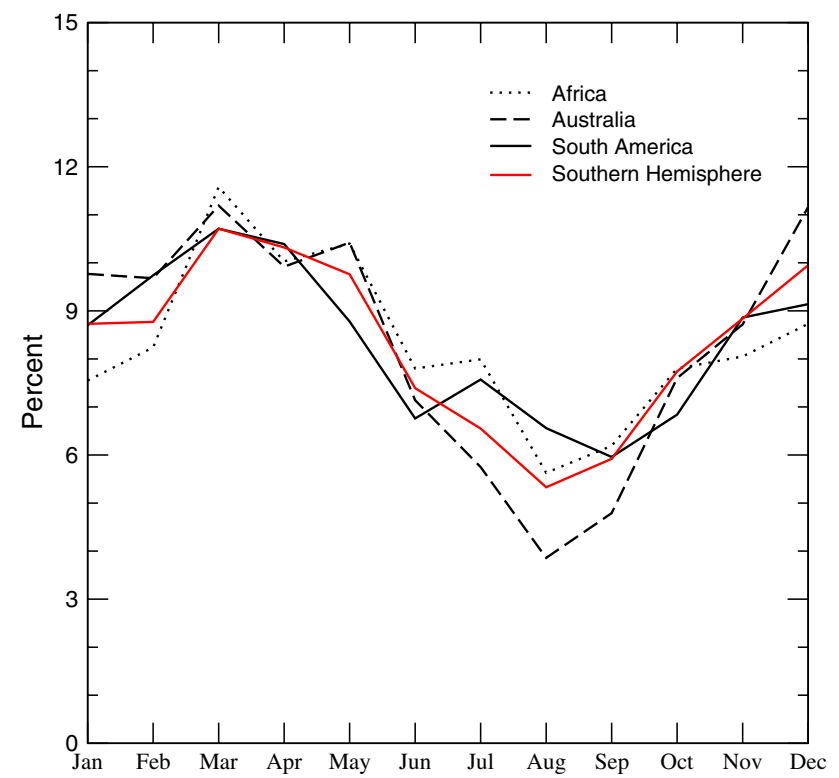

Fig. 3 Monthly distribution of the COL number expressed as a percentage of the absolute number of COLs for the African sector $\left(20^{\circ} \mathrm{W}-80^{\circ} \mathrm{E}\right)$ in dotted line, Australian sector $\left(80^{\circ} \mathrm{E}-140^{\circ} \mathrm{W}\right)$ in dashed line, South America sector $\left(140^{\circ} \mathrm{W}-20^{\circ} \mathrm{W}\right)$ in solid line, and Southern Hemisphere $\left(180^{\circ} \mathrm{W}-180^{\circ} \mathrm{E}\right)$ in red line, for the period from 1979 to 2014

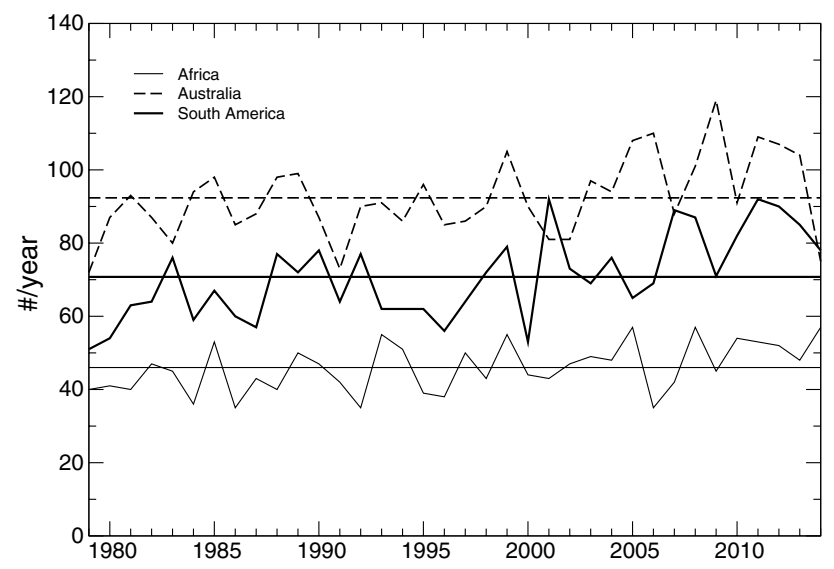

Fig. 4 Interannual distribution of the COL number for the African $\left(20^{\circ} \mathrm{W}-80^{\circ} \mathrm{E}\right)$, Australian $\left(80^{\circ} \mathrm{E}-140^{\circ} \mathrm{W}\right)$, and South America $\left(140^{\circ} \mathrm{W}-20^{\circ} \mathrm{W}\right)$ sectors, for the period from 1979 to 2014 . The line parallel to the $x$ axis represents the average of the total number of COLs

Australia (10.8) and Africa (6.7). The lowest annual number of COLs occurs in 1979 (235 cases) whereas 2008 is the most active year of COLs (337). In general, COLs are less frequent for the period 1979-1999 but they increase substantially from the early 2000s, and reach their maxima frequency in the three regions. The frequency of COLs increases by about $10 \%$ for the decade 2000-2009 in comparison to the decade $1980-1989$, but the increase is about $15 \%$ when considering only the South America sector. This result is in agreement with F12 and NW10, who show a positive trend in the number of COLs for the period 1979-2008.

According to F05, the spatial distribution of intensity, based on the Laplacian of the geopotential, showed no significant geographical variation. As opposed to the F05 results, the current distribution of COL mean intensity (Fig. 5), based on the MCRV scaled by -1 , exhibits a distinctive geographical and seasonal variability. The mean intensity values reach their minimum in the austral summer, but the values increase during the autumn and reach their peak in the winter. Also, the average intensity of COLs has its largest value more equatorward in winter, reaching the range of $10-12 \times 10^{-5} \mathrm{~s}^{-1}$ along the maximum track density region and the subtropical jet stream location (indicated by the zonal mean winds in Fig. 5). The mean intensities of COLs have a similar behavior but with weaker values in spring, with local maxima around $10 \times 10^{-5} \mathrm{~s}^{-1}$ in the neighborhood of the continents. In contrast, the mean intensities are lowest in summer with the peak values moving toward higher latitudes with values between 8 and $10 \times 10^{-5} \mathrm{~s}^{-1}$, coinciding with the average position of the jet stream.

The maximum intensity distribution of the COLs, determined by finding the maximum of the relative vorticity scaled by -1 along all tracks, is shown in Fig. 6. It is apparent that there is a broad range of intensities and significant differences between the seasons, with the most intense COLs occurring in winter, though COLs appear much less frequent in winter than in other seasons. For the spring, the maximum intensity distribution is similar but slightly weaker than autumn, while the weakest COLs are found in summer. These results are consistent with the spatial intensity statistic shown in Fig. 3. It is obvious that the seasonal intensity distribution based on vorticity is more sensitive than when the geopotential is used since it depends on second-order derivatives (Hoskins and Hodges 2002).

An interesting aspect is the preferred areas of COL genesis and lysis, i.e., where the systems originate and dissipate, respectively. These statistics are shown in Figs. 7 and 8 and are conveniently discussed together. The genesis and lysis densities are determined from the starting and ending locations of the COL tracks, respectively, excluding any tracks that start at the first time step and end at the last time step of the data period. It is worthwhile mentioning that the starting point does not necessarily represent a closed low at this specific time. The criteria used to detect COLs are imposed for at least four time steps, thus open depressions can be included in the early life cycle of the tracks. Note, lysis density values are somewhat larger than the genesis 


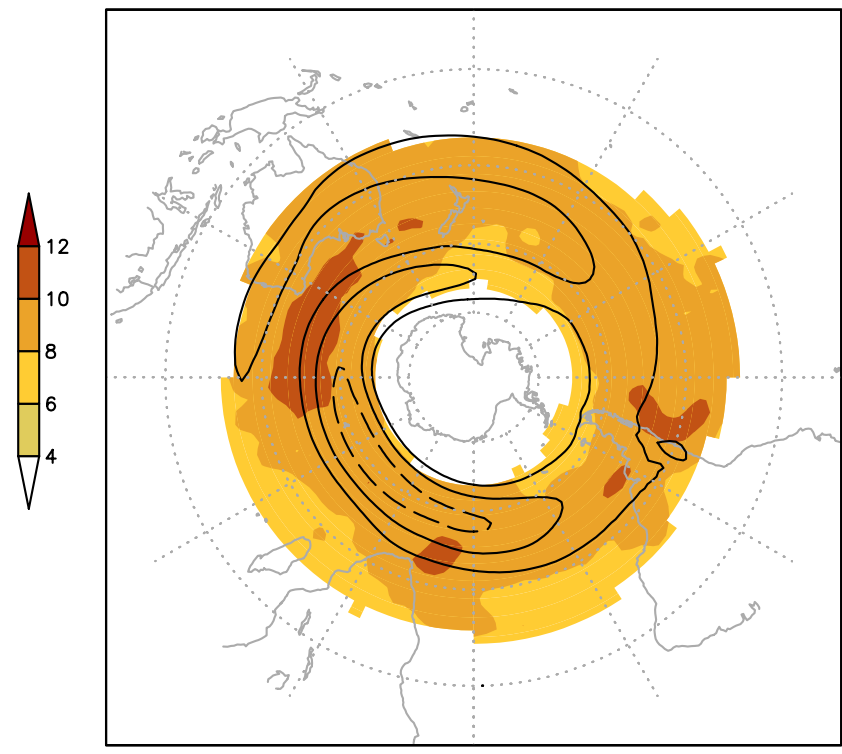

(a) Autumn

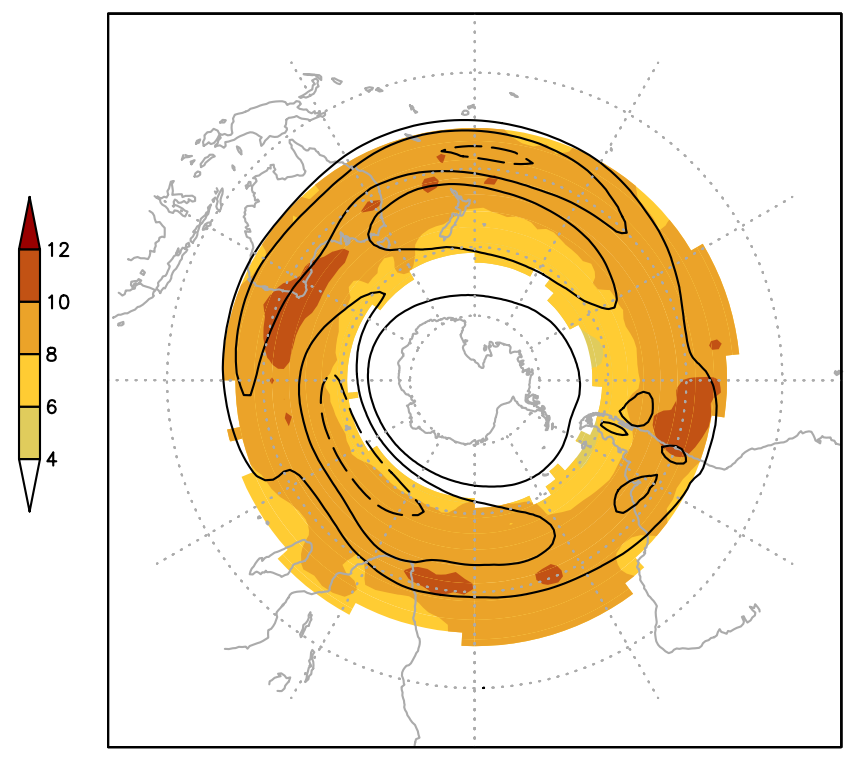

(c) Spring

Fig. 5 Seasonal Southern Hemisphere COL mean intensity (shaded) and mean zonal wind $\geq 80 \mathrm{~km} / \mathrm{h}$ (solid line) and $\geq 120 \mathrm{~km} / \mathrm{h}$ (dashed line) for the austral seasons: a autumn (MAM), b winter (JJA),

over specific regions, which means there are preferred regions where COLs often disappear.

It is apparent that there are two large lysis regions in the $\mathrm{SH}$. A maximum of lysis is found over the Andes in the austral summer and autumn, but this weakens at the beginning of the austral winter as seen in the monthly statistics (not shown). The COL lysis therefore seems to be strongly affected by the topography. This well-known regional feature has already been observed in F05 and a possible explanation is indicated by simply analyzing all

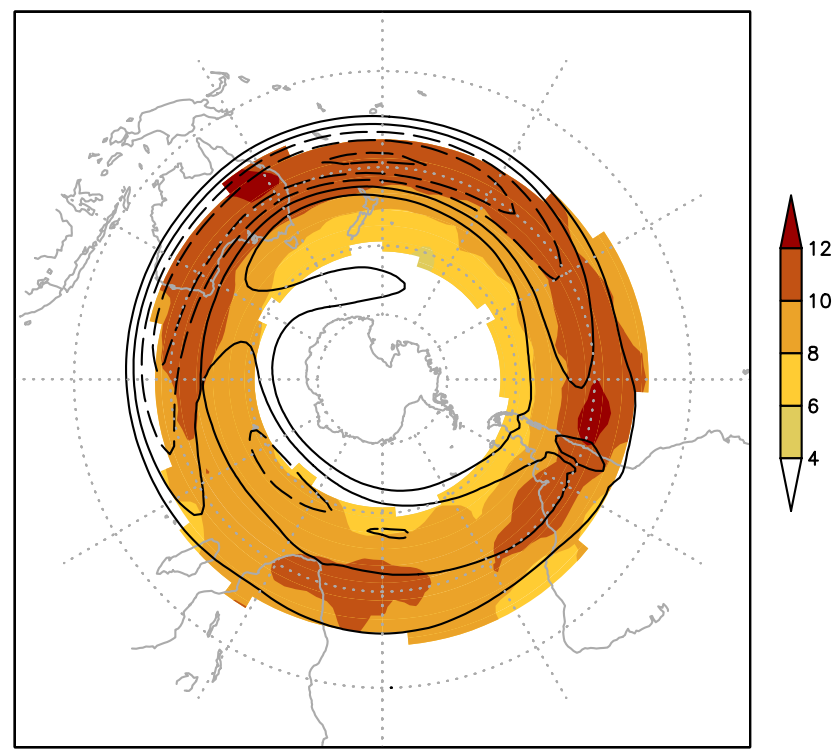

(b) Winter

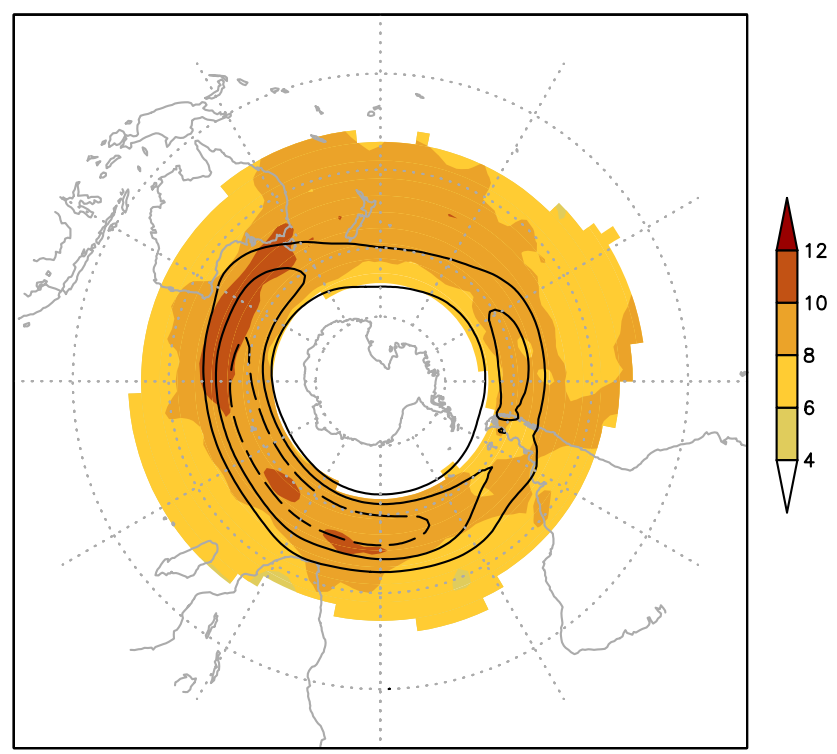

(d) Summer

c spring (SON), and d summer (DJF), period from 1979 to 2014. Unit: $10^{-} \mathrm{s}^{-1}$, scaled by -1

the statistics together. In the subtropical Andean region, summer COL intensities are relatively weak and most of them die out approaching the mountains. In contrast, winter COLs are stronger and the lysis associated with the Andes is quite negligible. This indicates that the mountain wave may interact with the COLs. When a COL approaches the mountain it weakens because of the superposition of the COL with the steady mountain wave ridge (topographic Rossby wave), as studied by Hayes et al. $(1987,1993)$ and observed by Miky Funatsu et al. (2004) over the Andes. 


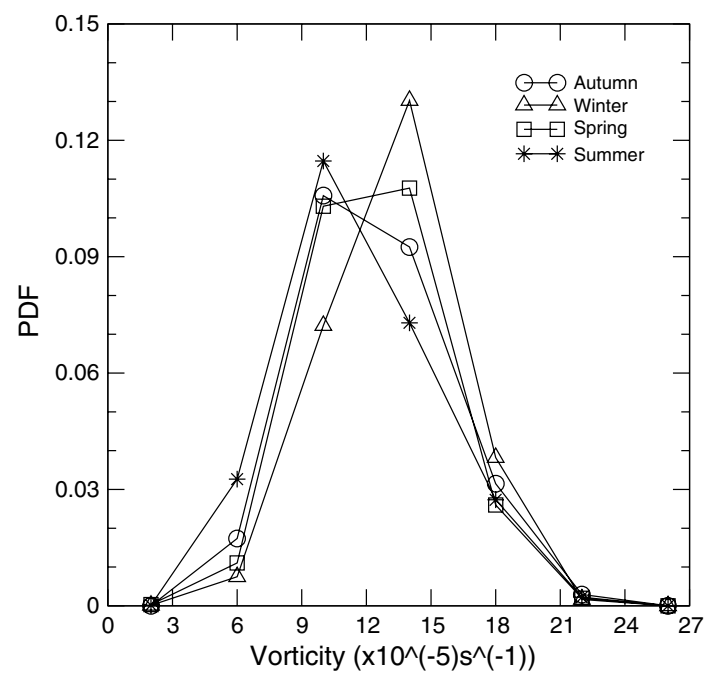

Fig. 6 Probability density distribution for seasonal maximum intensity of Southern Hemisphere COL based on vorticity tracks for the period from 1979 to 2014 . Unit: $10^{-5} \mathrm{~s}^{-1}$, scaled by -1

When the COL is weak it tends to dissipate. However, if the $\mathrm{COL}$ is strong enough, it dominates and after crossing the mountain ridge axis the COL can start a new intensification phase. Another prominent lysis region occurs from southeastern Australia and the Tasman Sea in autumn, which is the season of peak COL activity.

The genesis distribution is less heterogeneous than that for the lysis, although the genesis preferably occurs from Australia across the Pacific. The overall impression of lysis and genesis is that both coincide with the peak activity of COLs. Both of these density distributions show peaks of activity that are close to each other, suggesting the COLs are quasi-stationary systems (Bell and Bosart 1989) or a link may exist between lysis and genesis through downstream development (Orlanski and Sheldon 1995; Gan and Piva 2013).

The development of COLs is evaluated using the mean growth/decay rate (Fig. 9). This statistic represents the relative vorticity variation within a 6 hourly time step scaled to units of per day (Hoskins and Hodges 2002), negative values for weakening and positive values for intensifying systems. The mean growth rate shows enhanced values mainly at middle and high latitudes in the Atlantic and Indian Oceans, but these are not regions of large genesis. There is also growth activity in southern-southeastern Australia and across the central-southeastern Pacific. Focusing on South America, large growth appears where COLs in the Pacific Ocean are on the upstream side of the Andes and decay over the mountain. Also decay regions can be found at equatorward latitudes and from South Africa to Madagascar, western Australia, and New Zealand and environs, mainly from winter to spring. In general, the growth and decay predominates at poleward and equatorward latitudes, respectively. The main problem with the combined growth and decay rate is that there is lots of cancellation between positive and negative values, thus some growing and decaying regions can be masked out through this cancellation.

Tracks of COLs can be quite variable in terms of their speed of propagation. The zonal and meridional mean velocities of COLs are shown in Figs. 10 and 11, respectively. First, the zonal mean velocity shows that COLs usually move eastward for most of the year and are faster over higher latitudes. The maximum average zonal speed occurs in the Indian Ocean, with values greater than $60 \mathrm{~km} \mathrm{~h}^{-1}$. However, these features are associated with the late stage of the COLs life cycle and/or mid-latitude depressions, which should be ignored. In the subtropical and low latitude regions, there is a predominance of slow-moving systems, with velocities $\leq 30 \mathrm{~km} \mathrm{~h}^{-1}$. However, winter COLs generally move faster, even in subtropical latitudes, where they reach speeds in the range of $30-50 \mathrm{~km} \mathrm{~h}^{-1}$ in western Australia, western and central Pacific, and southeastern South America. It is interesting to note that the Pacific COLs have lower speeds as they approach the Andes, this is more noticeable from winter to spring. This could be the result of the mechanical effect associated with the mountains.

The meridional velocity shows a predominance of positive values in the SH, i.e., northward displacement. There is northward movement at the more southerly latitudes across the Indian Ocean and in southern Australia, whereas there is a southward component corresponding to the maximum lysis region, from north of New Zealand to the central Pacific. This feature is more evident in winter, suggesting that COLs move northeastward in the development phase and eastward/southeastward in the decaying phase. Similar but weaker behaviour can be seen in South America from winter to spring, when the COL tracks shift from northeastward on the western side of the Andes to eastward/southeastward on the lee side, as observed in F05. The possible mechanism responsible for the northeastward movement in the COL initial stage is the relative vorticity advection at upper levels, whereas the balance between the relative vorticity advection and the divergent terms is important to make the COL a quasi-stationary system during the cut-off and decay stages (Godoy et al. 2011).

The mean lifetime of COLs passing through a region (Fig. 12) is roughly uniform between 6 and 8 days. Lifetimes are shorter in winter (6.8 days) and longer in summer (7.6 days). Winter and summer also seem to be the periods with greatest difference in the lifetime spatial distribution, being lower around southeastern Australia and New Zealand, and higher over the South America as well as at higher latitudes, which is consistent with the longerlived mid-latitude COLs observed in the Northern Hemisphere (Kentarchos and Davies 1998). The average lifetime 


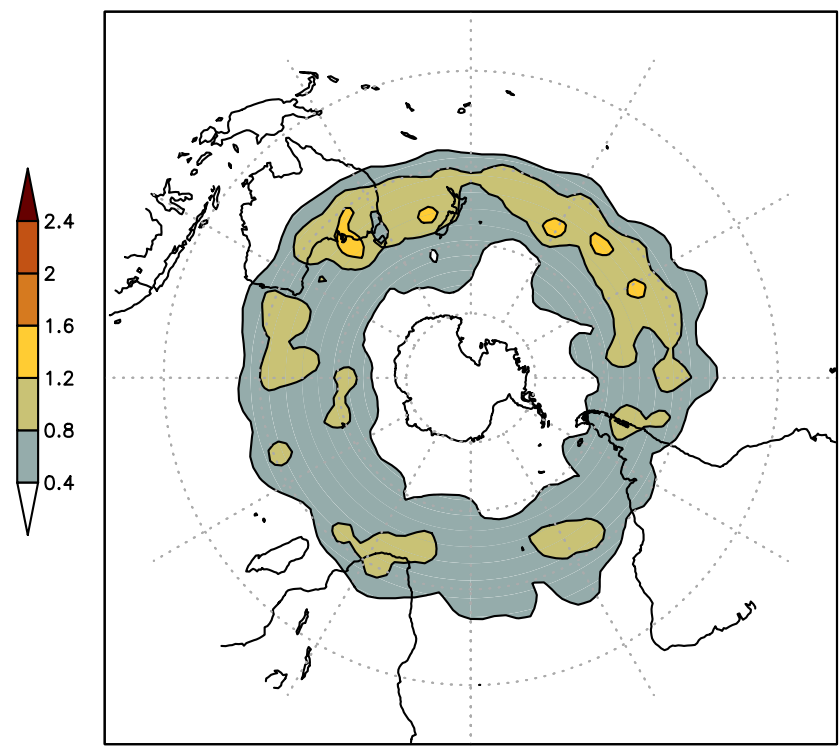

(a) Autumn

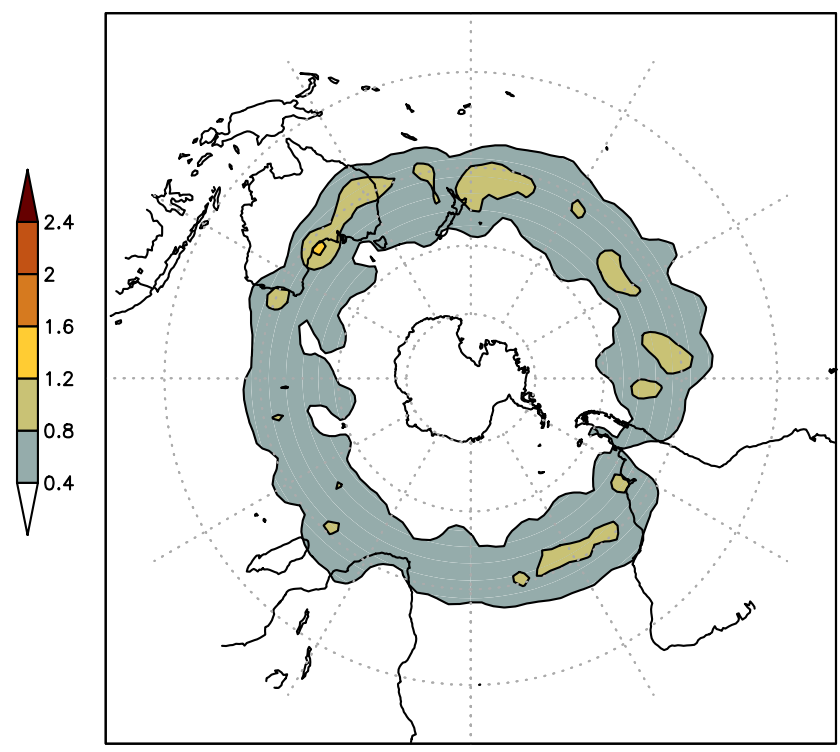

(c) Spring

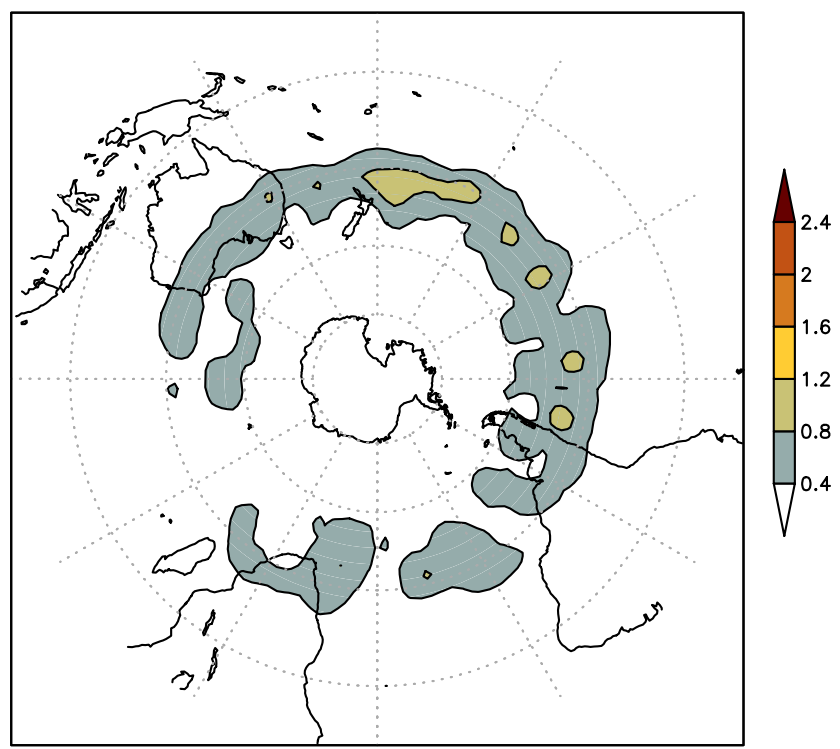

(b) Winter

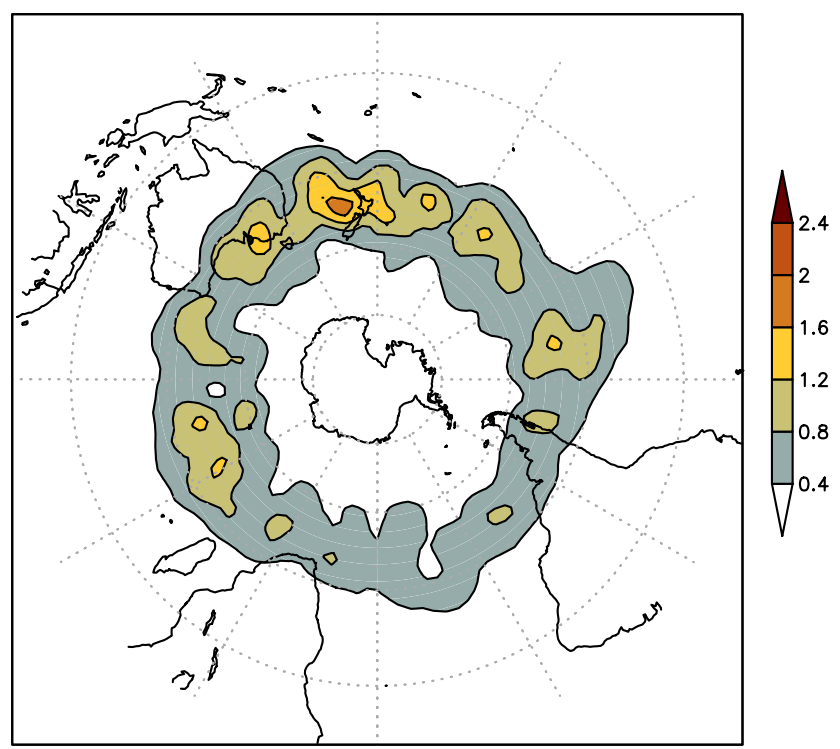

(d) Summer

Fig. 7 Seasonal average of Southern Hemisphere COL genesis rate for the austral seasons of a autumn (MAM), b winter (JJA), c spring (SON), and d summer (DJF), for the period from 1979 to 2014. It has the same unit as the track density

of features are much longer than found in previous studies (mostly around 2-3 days), and this is a consequence of the systems being identified earlier than when identifying COLs as geopotential minima. It is worth emphasizing that the longer lifetime does not affect the COLs total number. The densities produced by the algorithm do not include displacement features, but the combination of mean velocity and lifetime allow us to deduce that the mean displacement (figure not shown) is larger (smaller) in winter (summer), confirming what R10 have found.

\subsection{Comparison with previous studies}

Several climatological studies of COLs in the SH have been performed at different pressure levels using different methods and data sets as discussed above. In this section, comparisons of the COL temporal distribution between the results presented here and previous studies, based on upper pressure levels ( 300 or $250 \mathrm{hPa}$ ), will be performed. For the regional analysis focusing on Africa, Australia and South America sectors, we consider the same or the closest 




(a) Autumn

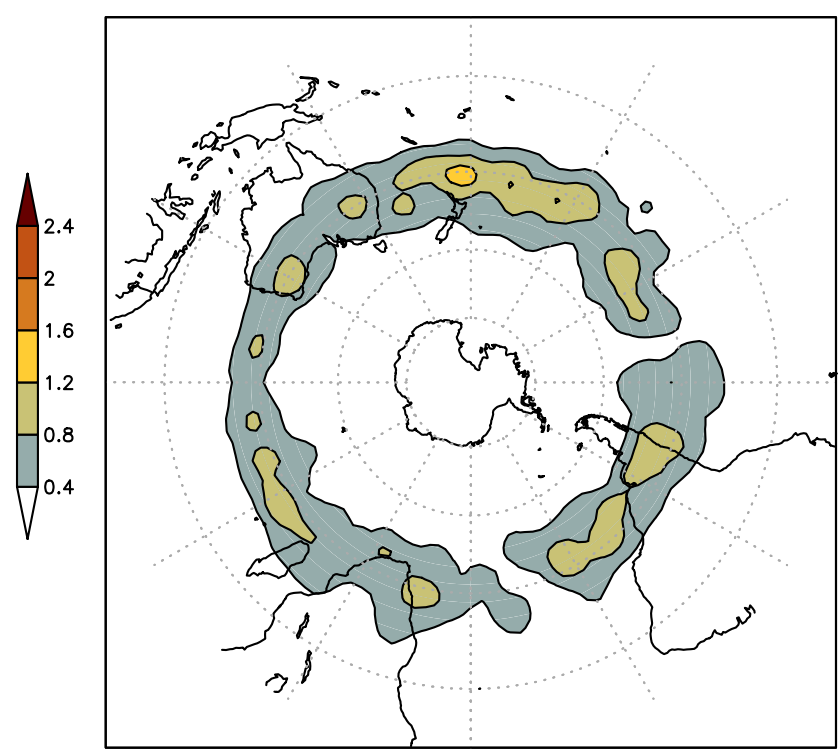

(c) Spring

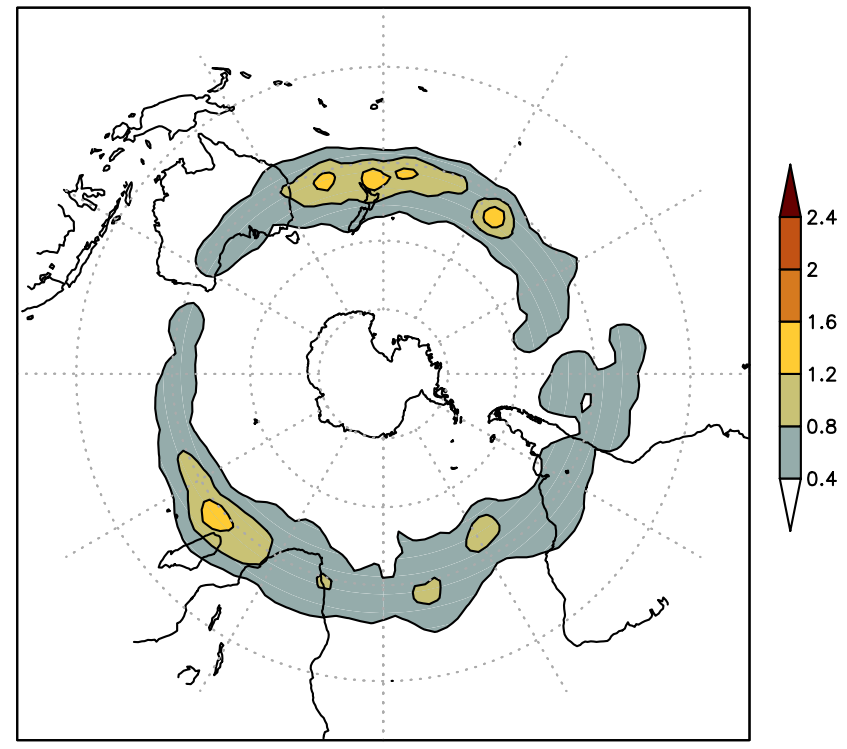

(b) Winter

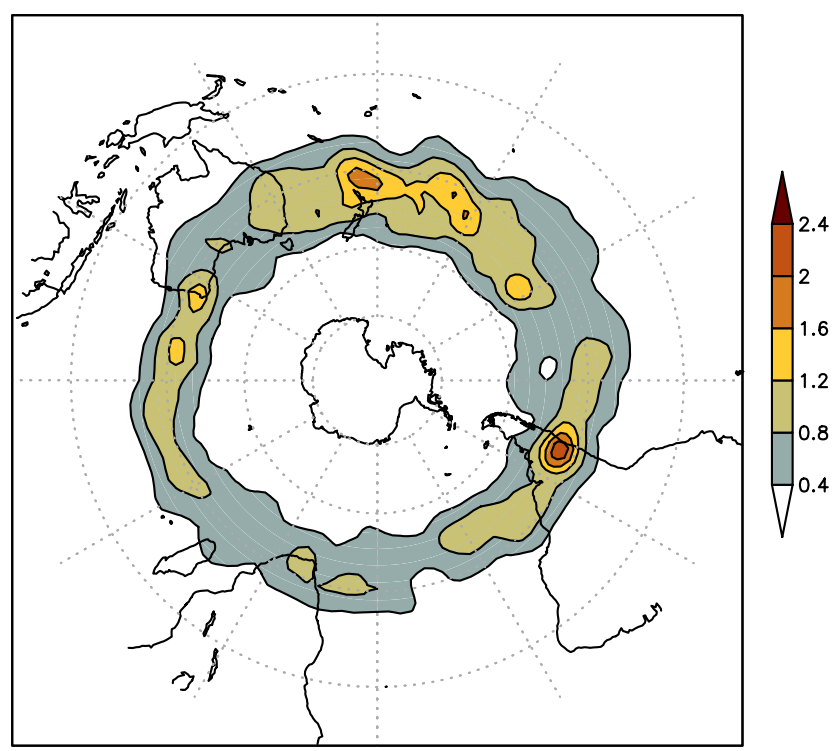

(d) Summer

Fig. 8 Seasonal average of Southern Hemisphere COL lysis rate for the austral seasons a autumn (MAM), b winter (JJA), c spring (SON), and d summer (DJF), for the period from 1979 to 2014. It has the same unit as the track density

domain and period used in the other studies. A summary of the main characteristics of each study on COL climatology is included in the Table 1.

The statistical study of CP07 presents a 10-year period (1979-1988) of the COL distribution for the southern South America $\left(100^{\circ} \mathrm{W}-20^{\circ} \mathrm{W}\right.$ and $\left.50^{\circ} \mathrm{S}-15^{\circ} \mathrm{S}\right)$ based on the NCEP-NCAR reanalysis (Kalnay et al. 1996). The CP07 method tracks COLs at $250 \mathrm{hPa}$ using a combination of subjective and objective methodology. They found the largest frequency in autumn, followed by winter, spring, and summer. Considering the same domain and period, we observed some differences in seasonality, that is, in descending order of frequency: summer, autumn, winter, and spring, although the differences among the seasons are not that large (not shown). These differences can be related to the dataset and/or criteria used for each method. In particular, the method of CP07 considers only the COLs associated with cold-cores and minimum thickness in the middle levels, both are features usually found in COLs at $500 \mathrm{hPa}$ (F05), and these are likely to be the reason why $\mathrm{CP} 07$ found that COLs are more frequent in winter than in summer. 


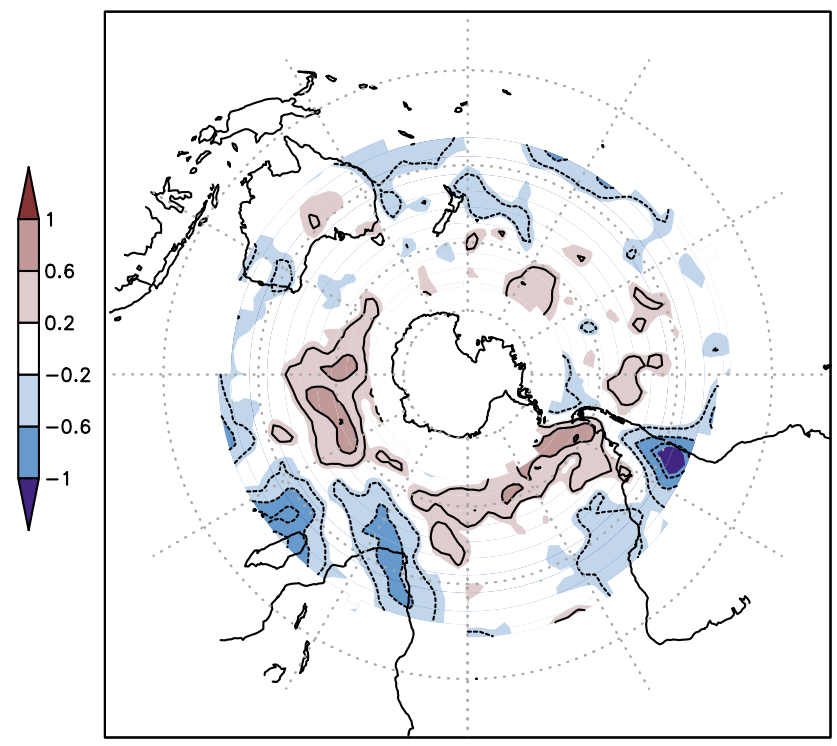

(a) Autumn

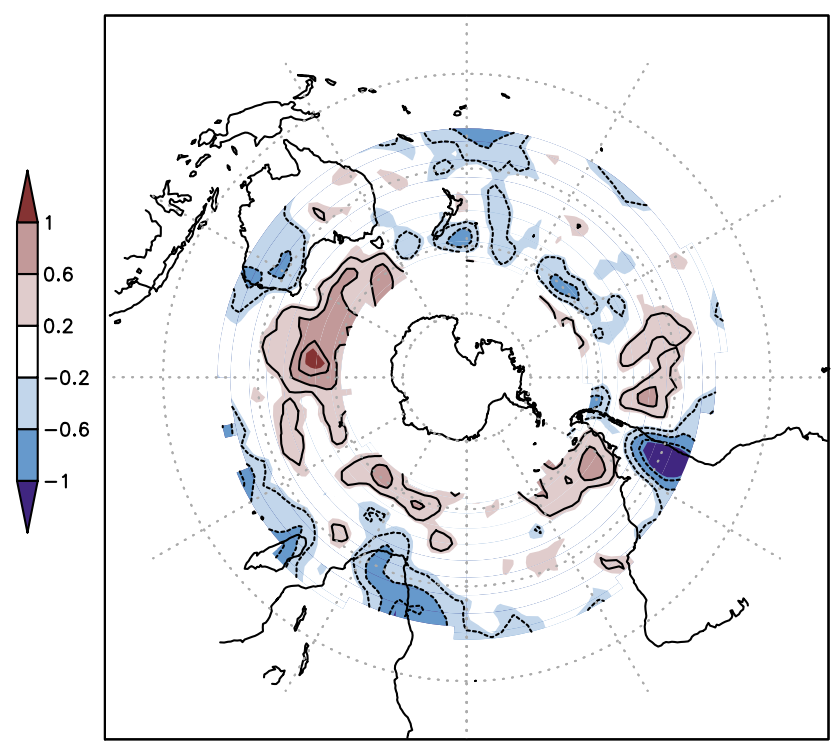

(c) Spring

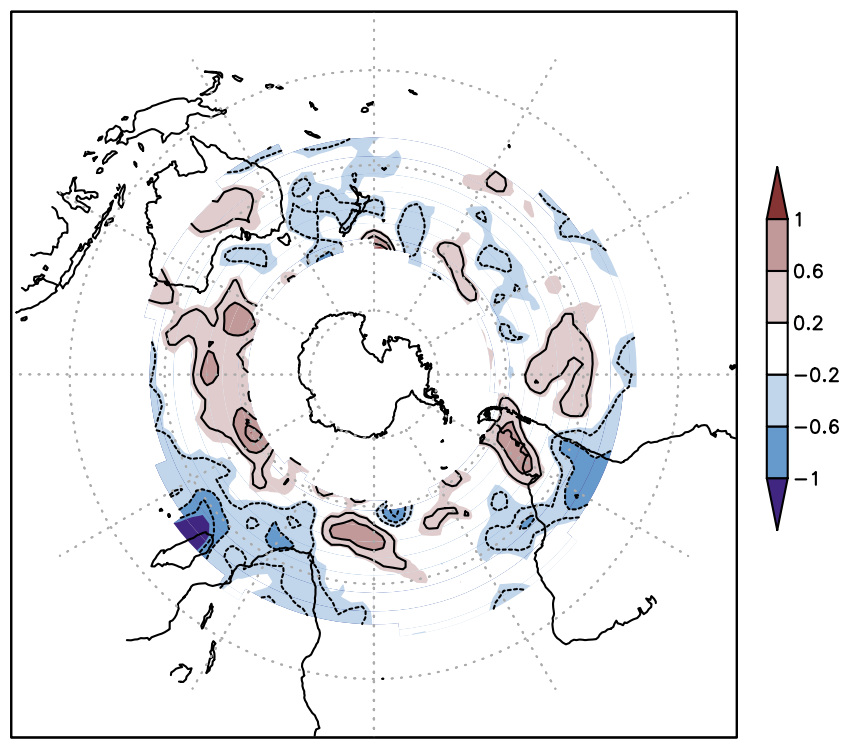

(b) Winter

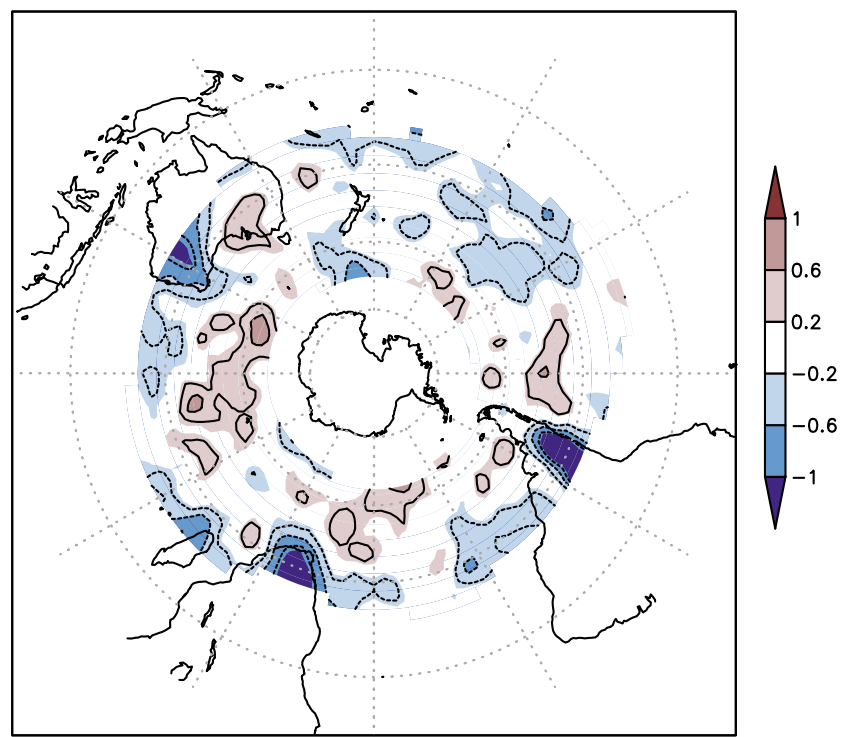

(d) Summer

Fig. 9 Seasonal average of Southern Hemisphere COL mean growth/decay rate for the austral seasons a autumn (MAM), b winter (JJA), c spring (SON), and d summer (DJF), for the period from 1979 to 2014. Unit: day ${ }^{-1}$

For a regional perspective, SR07 produced a 30-year (1973-2002) climatology of $300 \mathrm{hPa}$ COLs in southern Africa using the NCEP-NCAR reanalysis by a visual inspection of the geopotential field. They found the relative maximum in activity in autumn, followed by spring, winter, and summer, i.e., the same seasonality observed by Taljaard (1985) and confirmed in the present study, using the same domain but not the same period. Analyzing the COL monthly distribution, SR07 found the maximum occurrence in April and the minimum in December-January, a behavior quite similar to our study with the maximum occurring in March and the minimum in August.

The hemispheric climatology of R10 has been produced using two reanalyses (NCEP-NCAR and ERA-40), where COLs were identified using the algorithm of Nieto (Nieto et al. 2005) adapted to the SH. The seasonal cycle is analyzed for the three main regions, Africa $\left(20^{\circ} \mathrm{W}-60^{\circ} \mathrm{E}\right)$, Australia $\left(60^{\circ} \mathrm{E}-130^{\circ} \mathrm{W}\right)$, and South America $\left(130^{\circ} \mathrm{W}-20^{\circ} \mathrm{W}\right)$, for the latitudinal range of $50^{\circ} \mathrm{S}-10^{\circ} \mathrm{S}$ and a 21 -year period (1979-1999). For South America, the seasonality obtained 


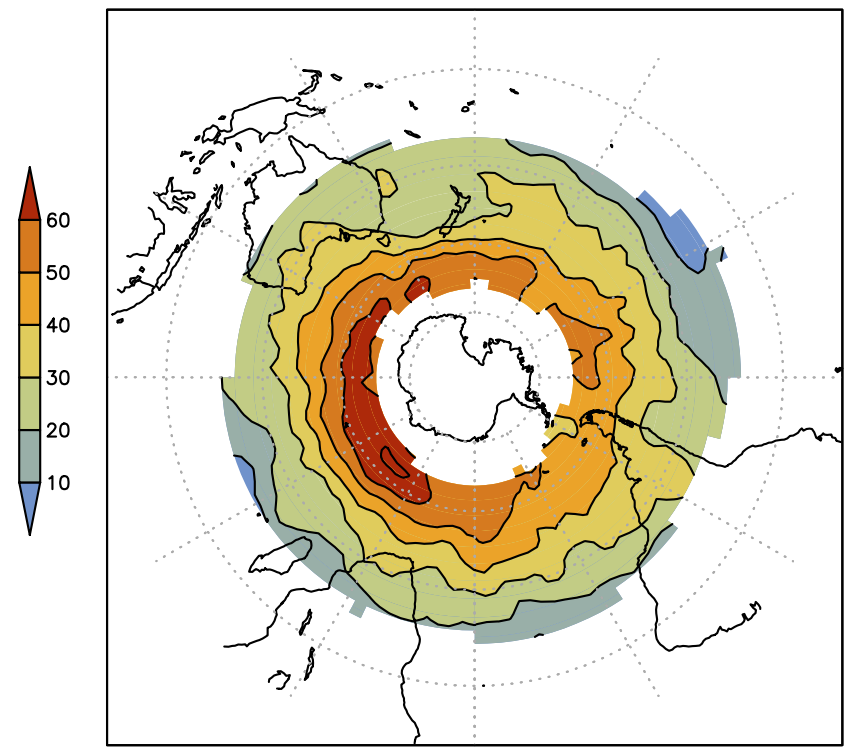

(a) Autumn

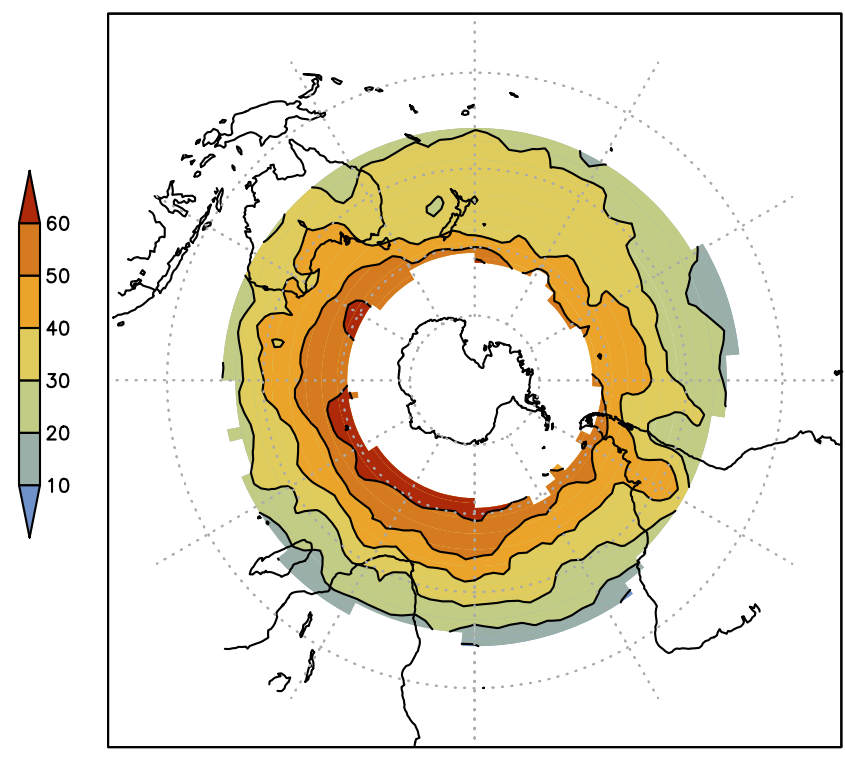

(c) Spring

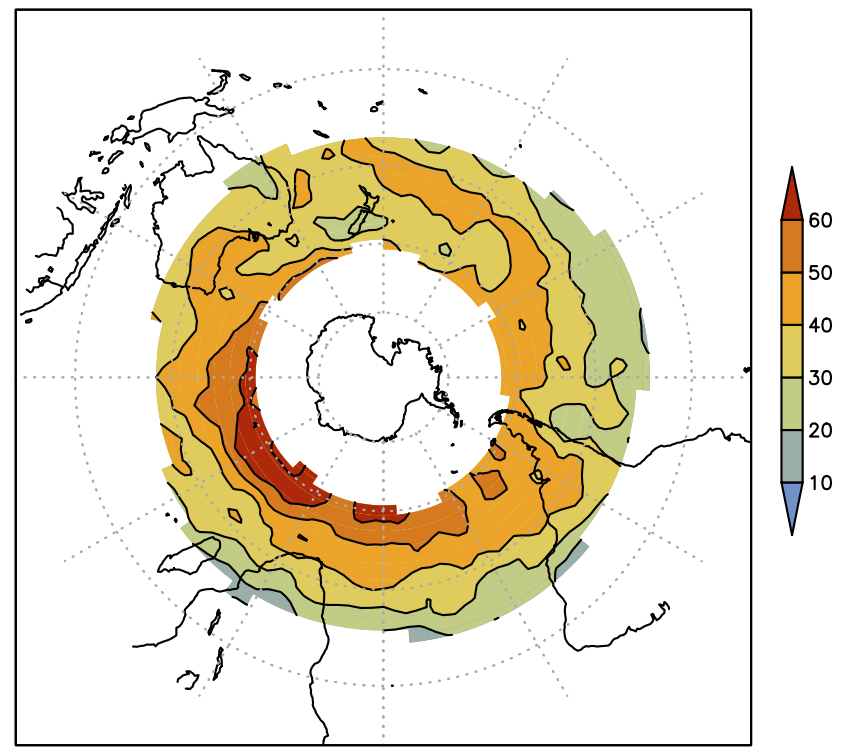

(b) Winter

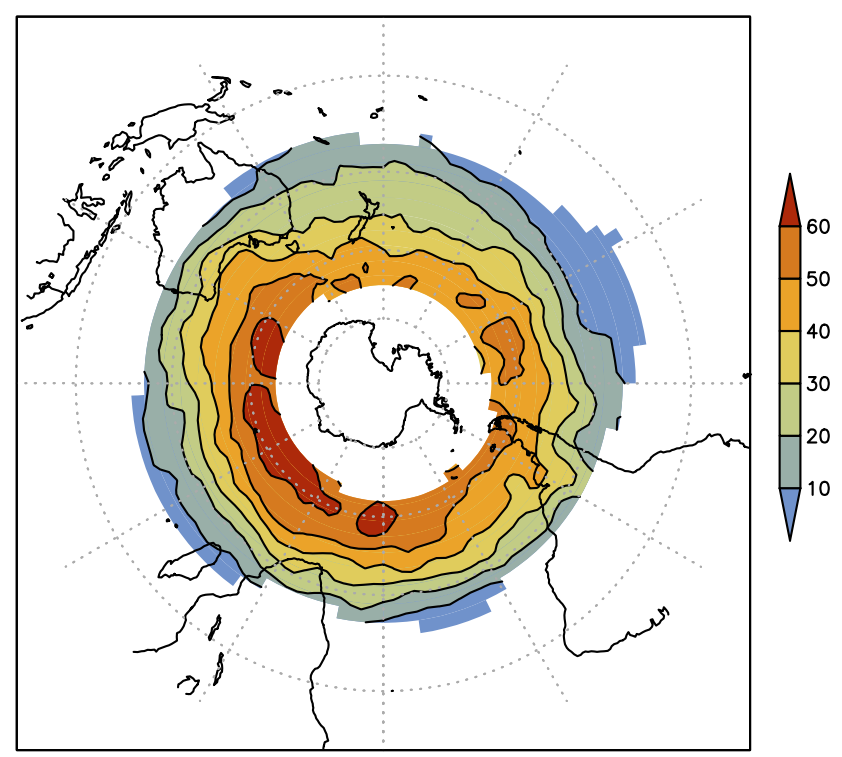

(d) Summer

Fig. 10 Seasonal average of Southern Hemisphere COL zonal mean velocity for the austral seasons a autumn (MAM), b winter (JJA), c spring (SON), and $\mathbf{d}$ summer (DJF), for the period from 1979 to 2014 . Unit: $\mathrm{km} \mathrm{h}^{-1}$

by R10 with ERA-40 is in fairly close agreement with our study (using the same domain and period), with the maximum in autumn, followed by summer, spring, and winter. However, the distribution they obtained with NCEP-NCAR differs widely since the highest (lowest) frequency occurs in autumn (summer). These results indicate that the differences between ERA-40 and NCEP-NCAR reanalyses found by R10 are greater than the differences between their and our identification methods using ERA-40 and ERA-I, respectively. This means that for the same pressure level the seasonality seems to be more dependent on the dataset than the criterion used for identifying COLs. Considering the Australia sector, the seasonality obtained in this study is consistent with R10 using ERA-40, where the maximum frequencies of COLs occurs in summer and autumn, and the minimum in spring and winter. However, the comparison between the present study and R10 with NCEP-NCAR is slightly different, because the latter climatology shows the largest frequency in autumn, followed by spring, summer, and winter. In terms of African COLs, our study is in agreement with R10 irrespective of the reanalysis used (ERA-40 or NCEP-NCAR), where the COL occurrence 


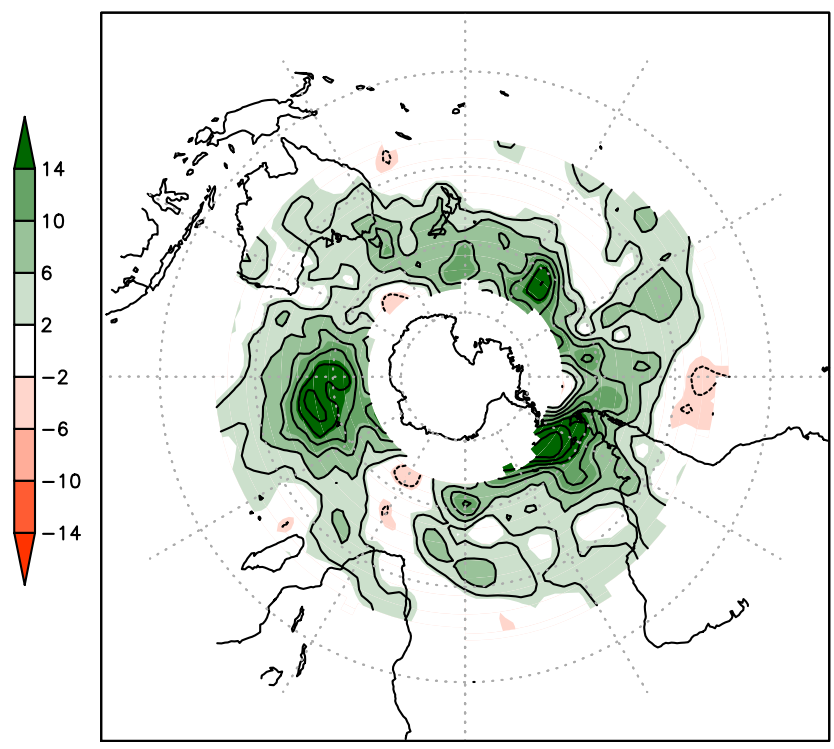

(a) Autumn

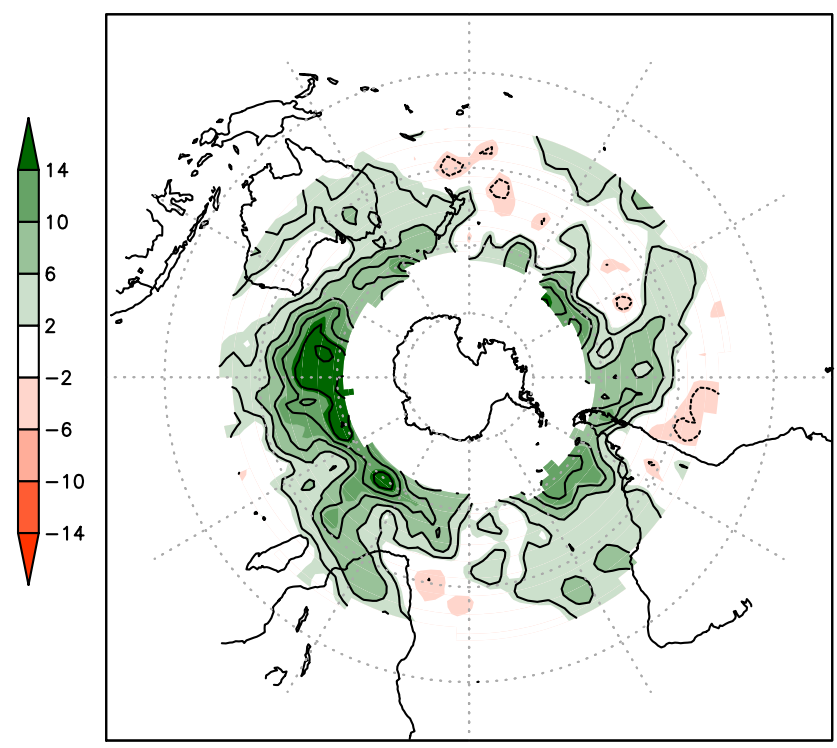

(c) Spring

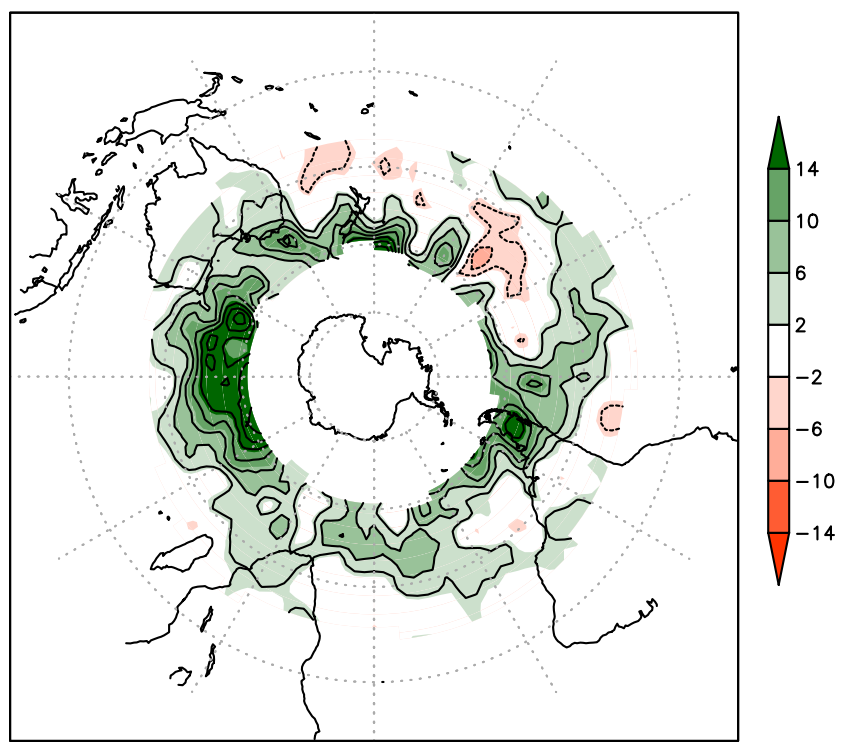

(b) Winter

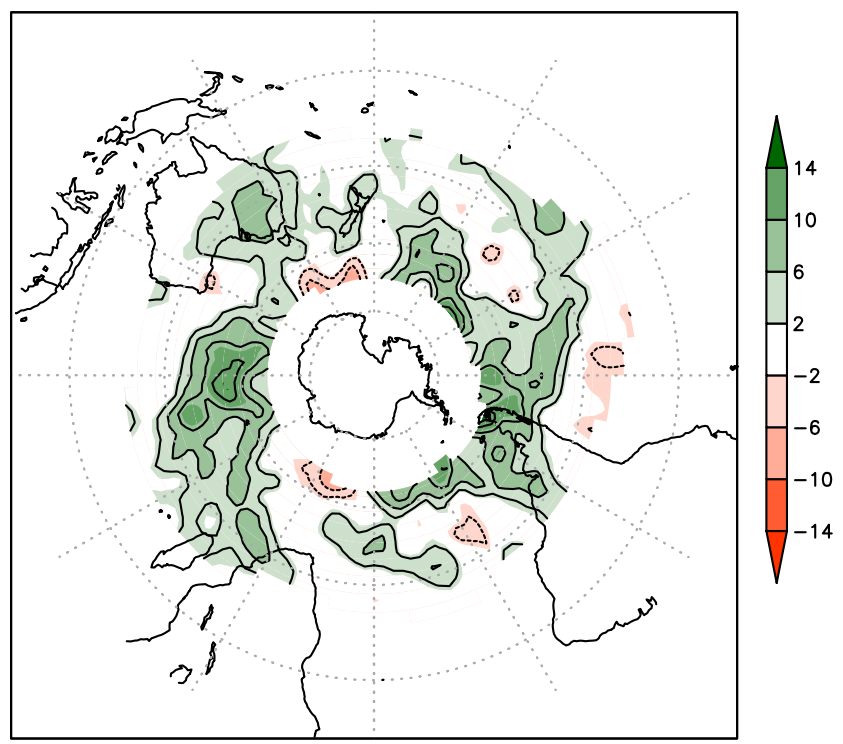

(d) Summer

Fig. 11 Seasonal average of Southern Hemisphere COL meridional mean velocity for austral seasons a autumn (MAM), b winter (JJA), c spring (SON), and d summer (DJF), for the period from 1979 to 2014 . Unit: $\mathrm{km} \mathrm{h}^{-1}$

is largest in autumn and spring and less frequent in summer and winter, providing more confidence in the results obtained here as they are also consistent with previous studies (e.g. Taljaard 1985; SR07), as seen before.

More recently, NW10 used a 30-year period (19792008) of NCEP-NCAR to produce a climatology of COLs at $250 \mathrm{hPa}$ linked to Rossby wave breaking (RWB) events. The method used to identify COLs is similar to that of Nieto et al. (2005) and R10, but has a modified criterion for the cold-core condition, where the thickness of $500-250 \mathrm{hPa}$ is compared between the geopotential height minimum and its surrounding points. They observed that COLs are more frequent in summer (maximum in December) and reach a minimum in winter (minimum in August), a seasonality somewhat different to ours, where the autumn is the most frequent season. However, for the COLs associated with the RWB at $330 \mathrm{~K}$ [where RWB is defined as an irreversible overturning of PV on isentropic surfaces (McIntyre and Palmer 1983)] the peak activity occurs in autumn (maximum in April), i.e., the same season observed in the present study. This helps us to understand some of the differences among the studies in terms of seasonality, 


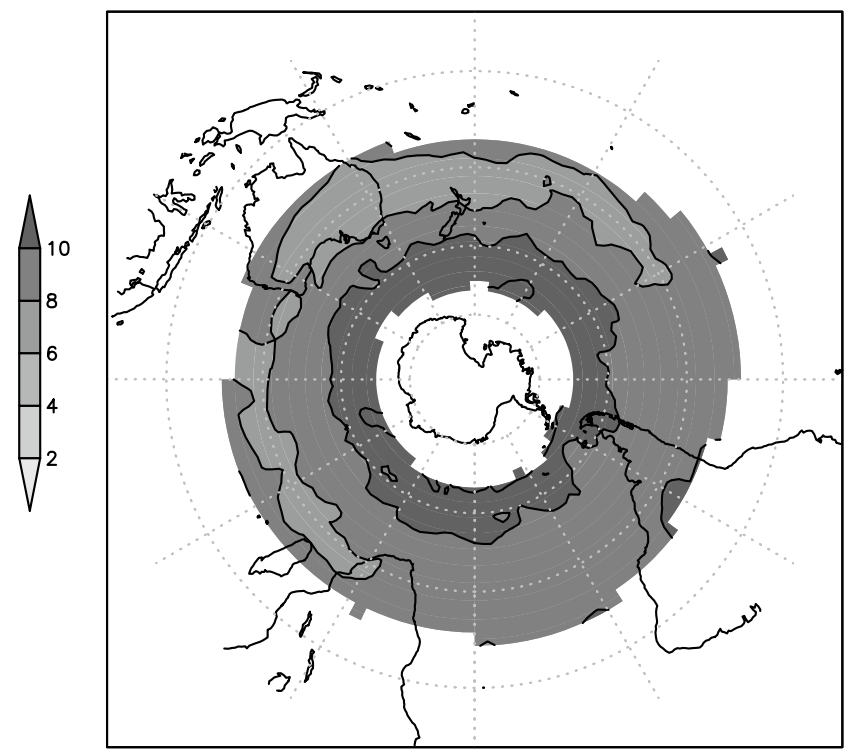

(a) Autumn

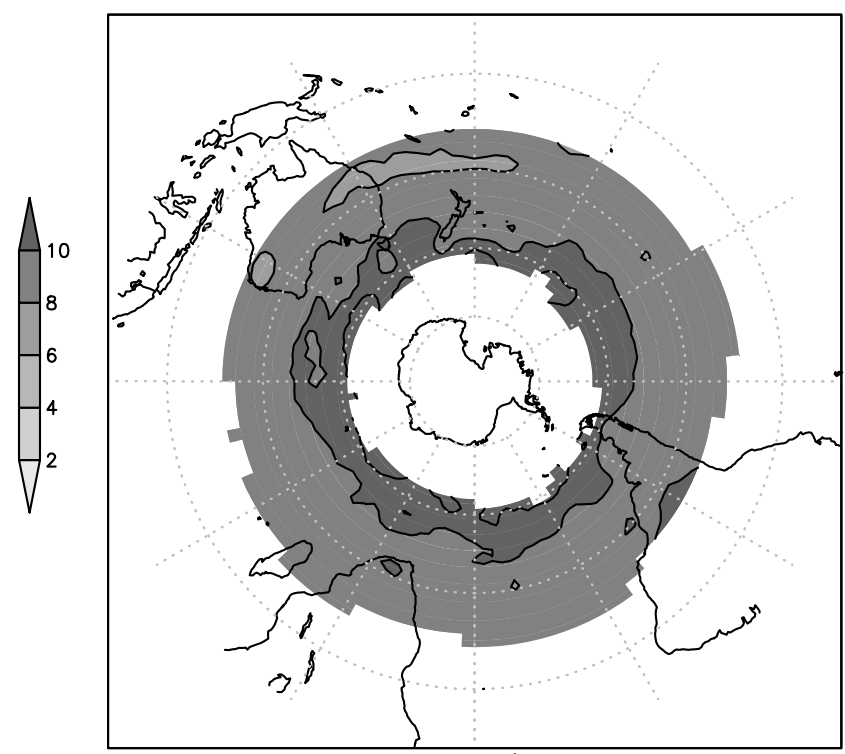

(c) Spring

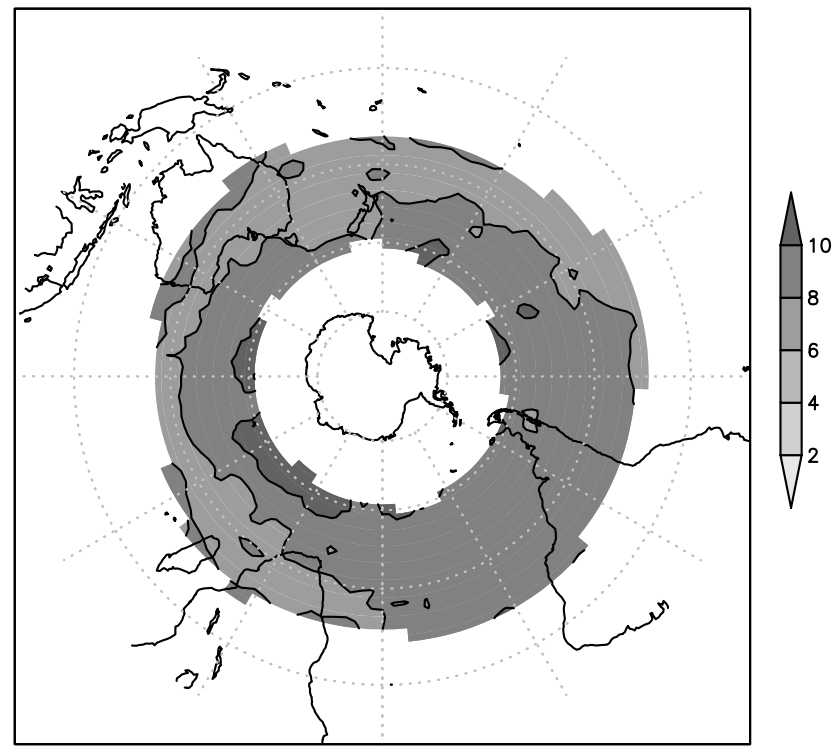

(b) Winter

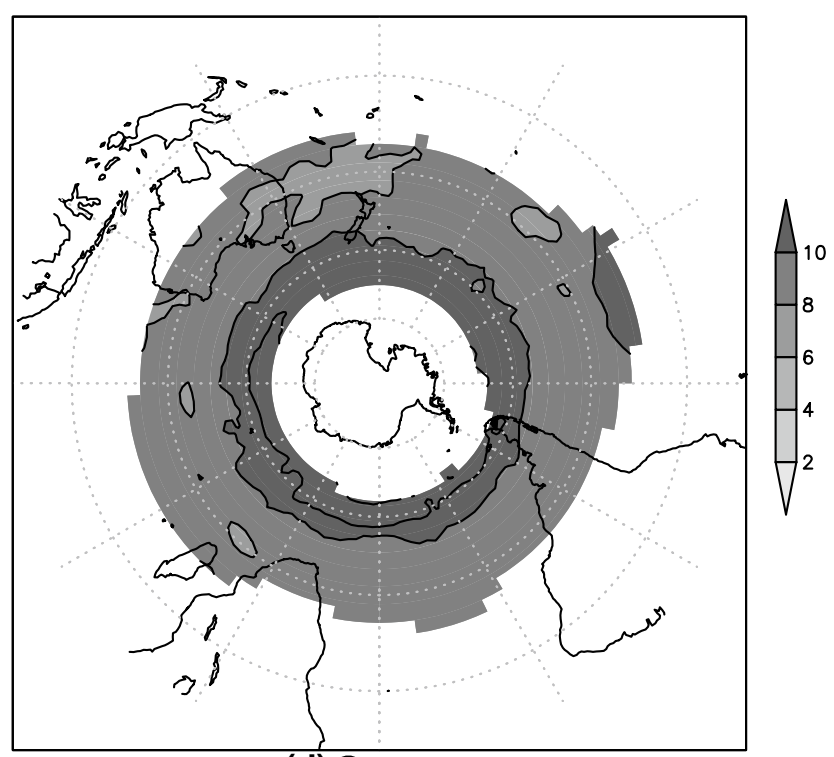

(d) Summer

Fig. 12 Seasonal average of Southern Hemisphere COL mean lifetime for the austral seasons a autumn (MAM), b winter (JJA), c spring (SON), and d summer (DJF), for the period from 1979 to 2014. Unit: day

and highlight how the PV anomalies associated with COLs represent important quantities for the COL identification.

An important point to consider is the differences in the number of COLs observed between previous studies. Considering the whole Southern Hemisphere, R10 show large differences in frequency when using the NCEP-NCAR and ERA-40 reanalyses, finding the annual average of COLs to be 197 using NCEP-NCAR and 349 using ERA-40. These values are much greater than the frequency observed by NW10 for COLs at $250 \mathrm{hPa}$ (120 events per year) using the NCEP-NCAR reanalysis and a tracking scheme similar to that used in R10, but with a more explicit imposition of the cold-core condition. For the study reported here the annual average of COLs is 285 but the frequency increases to 547 COLs per year if considering only the zonal wind criteria, that is with no cold core and PV criteria (figure not shown). However, the number of COLs reduces by about $25 \%$ when the tracking is performed using the geopotential field. The largest difference in track density between vorticity and geopotential occurs over areas of high density 
Table 1 Summary of the main characteristics of the previous studies on COL climatologies in the Southern Hemisphere, considering the approach, data, methodology, period and region used in each study

\begin{tabular}{|c|c|c|c|c|c|}
\hline References & Approach & Data & Methodology & Period & Region \\
\hline Fuenzalida et al. (2005) & Objective/subjective & NCEP-NCAR & $\begin{array}{l}\text { Geopotential minimum at } \\
500 \mathrm{hPa}\end{array}$ & 1969-1999 & $\begin{array}{l}\text { Southern Hemisphere } \\
\left(60^{\circ} \mathrm{S}-10^{\circ} \mathrm{S}\right)\end{array}$ \\
\hline $\begin{array}{l}\text { Campetella and Possia } \\
\text { (2007) }\end{array}$ & Objective/subjective & NCEP-NCAR & $\begin{array}{l}\text { Geopotential minimum at } \\
250 \mathrm{hPa}\end{array}$ & 1979-1988 & $\begin{array}{l}\text { South America } \\
\left(50^{\circ} \mathrm{S}-15^{\circ} \mathrm{S} / 100^{\circ} \mathrm{W}-20^{\circ} \mathrm{W}\right)\end{array}$ \\
\hline Singleton and Reason (2007) & Subjective & NCEP-NCAR & $\begin{array}{l}\text { Geopotential charts at } \\
300 \mathrm{hPa}\end{array}$ & 1973-2002 & $\begin{array}{l}\text { Southern Africa } \\
\left(40^{\circ} \mathrm{S}-20^{\circ} \mathrm{S} / 10^{\circ} \mathrm{E}-40^{\circ} \mathrm{E}\right)\end{array}$ \\
\hline Ndarana and Waugh (2010) & Objective & NCEP-NCAR & $\begin{array}{l}\text { Geopotential minimum at } \\
250 \mathrm{hPa}\end{array}$ & 1979-2008 & $\begin{array}{l}\text { Southern Hemisphere } \\
\left(50^{\circ} \mathrm{S}-20^{\circ} \mathrm{S}\right)\end{array}$ \\
\hline Reboita et al. (2010) & Objective & $\begin{array}{l}\text { NCEP-NCAR } \\
\text { ERA40 }\end{array}$ & $\begin{array}{l}\text { Geopotential minimum at } \\
200,300 \text {, and } 500 \mathrm{hPa}\end{array}$ & 1979-1999 & $\begin{array}{l}\text { Southern Hemisphere } \\
\left(50^{\circ} \mathrm{S}-10^{\circ} \mathrm{S}\right)\end{array}$ \\
\hline Favre et al. (2012) & Objective & NCEP-DOE II & $\begin{array}{l}\text { Geopotential minimum at } \\
500 \mathrm{hPa}\end{array}$ & 1979-2008 & $\begin{array}{l}\text { Southern Hemisphere } \\
\left(45^{\circ} \mathrm{S}-10^{\circ} \mathrm{S}\right)\end{array}$ \\
\hline
\end{tabular}

values though the differences are also remarkable in lower latitudes, where the geopotential gradient is usually weaker. More details on the difference between vorticity and geopotential will be discussed in a future paper.

Another reason for the differences in frequency of COLs is the pressure level chosen for the tracking, as pointed out in previous studies (e.g. R10). According to $\mathrm{R} 10$, the number of COLs at $300 \mathrm{hPa}$ is greater than those observed at 200 and $500 \mathrm{hPa}$, irrespective of the reanalysis used. In terms of the seasonal cycle, R10 found that the highest number of COLs at $500 \mathrm{hPa}$ occurs in winter and the lowest number in summer, confirming the results presented earlier by F05. However, the climatology of F12 contradicts the previous results, showing that the peak of the COL activity at $500 \mathrm{hPa}$ occurs in April and the minimum in August, i.e., a distribution similar to that observed for COLs at $300 \mathrm{hPa}$. These inconsistences suggest it is unclear whether the differences in seasonality of COLs are related to the method, data or pressure level used to identify COLs (see Table 1). Although an extensive climatology of COLs at 200, 300 and $500 \mathrm{hPa}$ has been presented in R10, the literature still lacks a comprehensive analysis of the vertical structure of COLs capable of showing how the high level COLs extend toward lower levels of troposphere.

As there is no absolute "truth" in terms of the number and seasonality of COLs, it is possible to say that there are pros and cons of using more complex criteria instead of simpler ones. Sensitivity tests show that the multiple step scheme identifies fewer events than the simpler method of no cold core test (figure not shown). However, the multiple step scheme allows us to identify only those systems that have the typical aspects of COLs (for example, cold core and stratospheric air intrusion), imposing specific features for the selected sample.

\section{Discussion and concluding remarks}

The use of the ERA-I reanalysis and the algorithm of Hodges (1995, 1996, 1999) adapted for tracking COLs provide a detailed perspective of the Southern Hemisphere COL activity at $300 \mathrm{hPa}$ for a 36-year period (1979-2014). COLs were identified using a multiple step scheme based on their main physical characteristics, such as cold-core and high-PV stratropheric air intrusion. The results of tracking COLs using $300 \mathrm{hPa}$ relative vorticity are in general agreement with previous studies based on the geopotential field, although the method detects longer lifetimes of COLs than seen in other studies as a consequence of using vorticity, as observed previously (Hoskins and Hodges 2002). However, the vorticity seems to have advantages over the geopotential field, because the former contributes to highlight the spatial and seasonal variation of the COL intensities.

A wide range of statistics has allowed us to explore the main COL characteristics, validating some previous results and revealing other interesting new COL properties. The track density shows that the largest number of COLs is found around the main continental areas (Australia, South America and Africa), confirming the previous results (e.g. F05; R10; NW10). In contrast, in summer the peak activity seems to migrate towards oceanic areas (Fig. 2), this behavior might be related to diabatic processes over the continents, corroborating the hypothesis proposed by Garreaud and Fuenzalida (2007). As discussed before, during the summer the latent heat associated with the cumulus convection tends to decrease the horizontal temperature across the COL cold-core, reducing the frequency of COLs over continents.

The T42 relative vorticity shows a marked geographical and seasonal variation, with minimum in summer and maximum in winter, a unique feature that has not been observed 
previously in studies based on the geopotential (e.g. F05). A possible link between the COL intensity and lysis density was examined, suggesting that weaker summer COLs are more susceptible to dissipate over mountainous regions (e.g. Andes). This means that large mountain ranges may influence the trajectories of COLs, especially for weaker systems. In general, lysis and genesis regions are close to each other and coincide with the feature density maxima, meaning the COLs are often quasi-stationary systems or alternatively there may exist a link between lysis and genesis through the theory of Downstream Development (Orlanski and Sheldon 1995). This latter hypothesis will be examined in a future study.

The mean growth/decay rates, based on the relative vorticity variation within the COL life cycle, coincide with the major genesis and lysis densities. In general, the growth predominates at poleward latitudes and the decay at equatorward latitudes. In terms of displacement, there is a significant seasonal variation of COL zonal mean velocity, they are faster over the higher latitudes, as suggested by F05. These results suggest that COLs move northeastward in the development phase and eastward/southeastward in the decay phase, as a result of the relative vorticity advection mechanism (Godoy et al. 2011).

The seasonal and monthly distribution of COLs shows a distinctive picture of the temporal variation in each region in the $\mathrm{SH}$, with the maximum activity found in autumn and summer, and the minimum usually in winter, opposite to that found for COLs at $500 \mathrm{hPa}$ (F05; R10). The monthly distribution of COLs compares better with the COLs linked to RWB events than the COLs without this link (NW10), suggesting that PV anomalies are an important factor that affect the seasonality of COLs. In addition, the seasonality of COLs in this study has shown a close agreement with that produced with ERA-40, but differs significantly when compared to the NCEP-NCAR climatology (R10). These results suggest that the uncertainties of reanalyses are important aspects to be considered since the seasonality has been shown to be largely dependent on the data as well as the method used to identify COLs.

Significant differences between ERA-40 and NCEPNCAR have also been observed in the NH for COLs (Nieto et al. 2008) and extratropical cyclones (Wang et al. 2006). The reason for the differences between the two mentioned reanalyses might be related to differences in how observations are assimilated by the two re-analyses as well as the model resolution. For example, the ERA-40 system uses the direct assimilation of satellite radiances (Uppala et al. 2005) whereas for NCEP-NCAR retrievals were used. However, there were problems with the assimilation of satellite humidity observations in ERA-40 (Bengtsson et al. 2004a), though this had the largest impact in the tropics.
Additionally, in the NCEP-NCAR reanalysis there was a problem involving the use of Australian bogus pressure data called PAOBS, in the SH (http://www.cpc.ncep.noaa. gov/products/wesley/paobs/ek.letter.html) though these observations have a low weight in the assimilation (Kistler et al. 2001). This is one of the benefits of using a more recent re-analysis where these problems have been rectified. The intercomparison among reanalyses with respect to COLs could be further studied in the future using other recent re-analysis in addition to ERA-I such as NCEPCFSR, NASA-MERRA and JRA55, such as has been performed more generally for extra-tropical cyclones (Hodges et al. 2011).

Another aspect of the temporal variability is the positive trend of COL frequency observed during the period 1979-2014, with a remarkable increase from the 2000s. This positive trend has already been pointed out by F12 and Ndarana et al. (2012), F12 suggested the increase might be linked to the rising of surface pressure and the formation of cut-off highs in mid-latitudes. However, it is also important to consider the issues with the assimilation of observations commented above, in particular from satellites which have changed over time, with more observation being used for the latter years and of a better quality. It is well known that re-analyses can have spurious trends and is a particular problem in the SH (Bengtsson et al. 2004b). Another point to consider here is the natural variability of COLs, the dataset is too short to say much on this. Using a longer data set such as the twentieth-century reanalysis (Compo et al. 2011) would not be appropriate for this purpose as only surface observations are assimilated, which are sparse in the $\mathrm{SH}$, and there are considerable changes in the observation distribution with time both of which are likely to lead to spurious trends and variability, in particular in the upper troposphere.

It is important to mention that the present study focuses only on the aspects of COLs at $300 \mathrm{hPa}$. In future work, we intend to consider the vertical structure of subtropical COLs and its relation to the precipitation.

Open Access This article is distributed under the terms of the Creative Commons Attribution 4.0 International License (http://creativecommons.org/licenses/by/4.0/), which permits unrestricted use, distribution, and reproduction in any medium, provided you give appropriate credit to the original author(s) and the source, provide a link to the Creative Commons license, and indicate if changes were made.

\section{References}

Ancellet G, Beekmann M, Papayiannis A (1994) Impact of a cutoff development on downward transport of ozone in the stratosphere. J Geophys Res 99:3451-3463. doi:10.1029/93JD02551 
Bell GD, Bosart LF (1989) A 15-year climatology of Northern Hemisphere $500 \mathrm{mb}$ closed cyclone and anticyclone centers. Mon Wea Rev 117:2142-2163. doi:10.1175/1520-0493(1989)117<2142:AYCONH>2.0.CO;2

Bell GD, Bosart LF (1993) A case study diagnosis of the formation of an upper-level cut off cyclonic circulation over the eastern united states. Mon Wea Rev 121:1635-1655. doi:10.1175/1520-0493(1993)121<1635:ACSDOT>2.0.CO;2

Bell GD, Keyser D (1993) Shear and curvature vorticity and potential vorticity interchanges: interpretation and application to a cut-off cyclone event. Mon Wea Rev 121:76-102

Bengtsson L, Hodges KI, Hagemann S (2004a) Sensitivity of the ERA40 reanalysis to the observing system: determination of the global atmospheric circulation from reduced observations. Tellus 56A:456-471. doi:10.1111/j.1600-0870.2004.00079.x

Bengtsson L, Hagemann S, Hodges KI (2004b) Can climate trends be calculated from reanalysis data? J Geophys Res Atmos 109:D11111. doi:10.1029/2004JD004536

Campetella C, Possia N (2007) Upper-level cut-off lows in southern South America. Meteor Atmos Phys 96:181-191. doi:10.1007/ s00703-006-0227-2

Compo GP, Whitaker JS, Sardeshmukh PD, Matsui N, Allan RJ, Yin $\mathrm{X}$, Gleason BE, Vose RS, Rutledge G, Bessemoulin P, Brönnimann S, Brunet M, Crouthamel RI, Grant AN, Groisman PY, Jones PD, Kruk M, Kruger AC, Marshall GJ, Maugeri M, Mok HY, Nordli $\varnothing$, Ross TF, Trigo RM, Wang XL, Woodruff SD, Worley SJ (2011) The twentieth century reanalysis project. Q J R Meteor Soc 137:1-28. doi:10.1002/qj.776

Cuevas E, Rodríguez J (2002) Estadística de depresiones aisladas em niveles altos. Terceira Assembléia Hispano Portuguesa de Geodésia e Geofísica. Comissão Espanhola de Geodésia e Geofísica, Valencia, Spain, 1-3

Davies TD, Schuepbach E (1994) Episodes of high ozone concentrations at the Earth's surface resulting from transport down from the upper troposphere/lower stratosphere: a review and case studies. Atmos Environ 28:53-68. doi:10.1016/1352-2310(94)90022-1

Favre A, Hewitson B, Tadross M, Lennard C, Cerezo-Mota R (2012) Relationships between cut-off lows and the semiannual and southern oscillations. Clim Dyn 38:1473-1487. doi:10.1007/ s00382-011-1030-1034

Fuenzalida HA, Sánchez R, Garreaud RD (2005) Climatology of cutoff lows in the Southern Hemisphere. J Geophys Res 110:1-10. doi:10.1029/2005JD005934

Gan MA, Piva E (2013) Energetics of a southeastern Pacific cut-off low. Atmos Sci Lett 14:272-280. doi:10.1002/as12.451

Garreaud RD, Fuenzalida HA (2007) The influence of the Andes on cutoff lows: a modeling study. Mon Wea Rev 15:1596-1613. doi:10.1175/MWR3350.1

Godoy AA, Possia NE, Campetella CM, Skabar YG (2011) A cut-off low in southern South America; dynamic and thermodynamic processes. Revista Brasileira de Meteorologia 26:503-514. doi:10.1590/S0102-77862011000400001

Hayes JL, Williams RT, Rennick MA (1987) Lee cyclogenesis. Part I: analytic studies. J Atmos Sci 44:432-442. doi:10.1175/1520-0469(1987)044<0432:LCPIAS>2.0.CO;2

Hayes JL, Williams RT, Rennick MA (1993) Lee cyclogenesis. Part II: numerical studies. J Atmos Sci 50:2354-2368. doi:10.1175/1520-0469(1993)050<2354:LCPINS>2.0.CO;2

Hernández A (1999) Un estudio estadístico sobre Depresiones Aisladas en Niveles Altos (DANAS) en el sudoeste de Europa basado en mapas isentrópicos de vorticidad potencial. IV Simposio Nacional de Predicción, Madrid, pp 235-240

Hodges KI (1994) A general method for tracking analysis and its application to meteorological data. Mon Wea Rev 122:2573-2585. doi:10.1175/1520-0493(1994)122<2573:AGMFTA>2.0.CO;2
Hodges KI (1995) Feature tracking on the unit sphere. Mon Wea Rev 123:3458-3465. doi:10.1175/1520-0493(1995)123<3458:FTOT $\mathrm{US}>2.0 . \mathrm{CO} ; 2$

Hodges KI (1996) Spherical nonparametric estimators applied to the UGAMP model integration for AMIP. Mon Wea Rev 124:2914 2932. doi:10.1175/1520-0493(1996)124<2914:SNEATT>2.0.CO2

Hodges KI (1999) Adaptive constraints for feature tracking. Mon Wea Rev 127:1362-1373. doi:10.1175/1520-0493(1999)127<1362:ACFFT>2.0.CO;2

Hodges KI, Lee RW, Bengtsson L (2011) A comparison of extratropical cyclones in recent reanalyses ERA-Interim, NASA MERRA, NCEP CFSR, and JRA-25. J Clim 24:4888-4906. doi:10.1175/2 011JCLI4097.1

Holton J, Haynes P, Mcintyre M, Douglass AR, Rood RB, Pfister L (1995) Stratosphere-troposphere exchange. Rev Geophys 33:403-439

Hoskins BJ, Hodges KI (2002) New perspectives on the northern hemisphere winter storm tracks. J Atmos Sci 59:1041-1061. doi:10.1175/1520-0469(2002)059<1041:NPOTNH >2.0.CO;2

Hoskins BJ, Hodges KI (2005) A new perspective on the southern hemisphere winter storms tracks. J Clim 18:4108-4129. doi:10.1175/1520-0469(2002)059<1041:NPOTNH >2.0.CO;2

Hoskins BJ, Mcintyre ME, Robertson AW (1985) On the use and significance of isentropic potential vorticity maps. Q J R Meteor Soc 111:877-946. doi:10.1002/qj.49711147002

Kalnay $E$ et al (1996) The NCEP-NCAR 40-Year reanalysis Project. Bull Am Meteor Soc 77:437-471. doi:10.1175/1520-0477(1996)077<0437:TNYRP>2.0.CO;2

Kanamitsu M, Ebisuzaki W, Woollen J, Yang S-K, Hnilo JJ, Fiorino M, Potter GL (2002) NCEP-DOE AMIP-II reanalysis (R-2). Bull Am Meteor Soc 83:1631-1643. doi:10.1175/BAMS-83-11-1631

Kentarchos AS, Davies TD (1998) A climatology of cutoff lows at $200 \mathrm{hPa}$ in the Northern Hemisphere, 1990-1994. Int J Climatol 18:379-390. doi:10.1002/ (SICI)1097-0088(19980330)18:4<379:AID-JOC257>3.0.CO;2-F

Kistler R, Collins W, Saha S, White G, Woollen J, Kalnay E, Chelliah M, Ebisuzaki W, Kanamitsu M, Kousky V, Van Den Dool H, Jenne R, Fiorino M (2001) The NCEPNCAR 50-year reanalysis: monthly means CD-ROM and documentation. Bull Am Meteor Soc 82:247-267. doi:10.1175/1520-0477(2001)082<0247:TNNYRM>2.3.CO;2

Kousky VE, Gan MA (1981) Upper tropospheric cyclonic vortices in the subtropical South Atlantic. Tellus 33:538-551. doi:10.1111/j.2153-3490.1981.tb01780.x

Marques RFC, Rao VB (2000) Interannual variations of blocking in the Southern Hemisphere and their energetics. J Geophys Res 105:4625-4636. doi:10.1029/1999JD901066

McIntyre ME, Palmer TN (1983) Breaking planetary waves in the stratosphere. Nature 305:593-600. doi:10.1038/305593a0

Miky Funatsu B, Gan MA, Caetano E (2004) A case study of orographic cyclogenesis over South America. Revista Atmosfera 17:91-113

Mishra SK, Rao VB, Gan MA (2001) Structure and evolution of the large scale flow and an embedded upper tropospheric cyclonic vortex over Northeast Brazil. Mon Wea Rev 129:1673-1688. doi:10.1175/1520-0493(2001)129<1673:SAEOTL >2.0.CO;2

Ndarana T, Waugh DW (2010) The link between cut-off lows and Rossby wave breaking in the Southern Hemisphere. Q J R Meteor Soc 136:869-885. doi:10.1002/qj.627

Ndarana T, Waugh DW, Polvani LM, Correa GJP, Gerber EP (2012) Antarctic ozone depletion and trends in tropopause Rossby wave breaking. Atmos Sci Lett 13:164-168. doi:10.1002/asl.384

Nieto R et al (2005) Climatological features of cutoff low systems in the Northern Hemisphere. J Clim 18:3085-3103. doi:10.1175/ JCLI3386.1 
Nieto R, Sprenger M, Wernli H, Trigo RM, Gimeno L (2008) Identification and climatology of cut-off low near the topopause. Ann New York Acad Sci 1146:256-290. doi:10.1196/annals.1446.016

Orlanski I, Sheldon J (1995) Stages in the energetics of baroclinic systems. Tellus 47:605-628

Palmén E, Newton CW (1969) Atmospheric circulation systems, their structure and physical interpretation. Academic Press. doi:10.1034/j.1600-0870.1995.00108.x

Pizarro JG, Montecinos A (2000) Cutoff cyclones off the subtropical coast of Chile, Sixth international conference on southern hemisphere meteorology and oceanography, Santiago, Chile. American Meteorological Society, pp 278-279

Price JD, Vaughan G (1992) Statistical studies of cut-off low systems. Ann Geophys 10:96-102

Reboita MS, Nieto R, Gimeno L, Rocha RP, Ambrizzi T, Garreaud R, Kruger LF (2010) Climatological features of cutoff low systems in the Southern Hemisphere. J Geophys Res 115:D17104. doi:10. 1029/2009jd013251

Satyamurty P, Seluchi ME (2007) Characteristics and structure of an upper air cold vortex in the subtropics of South America. Meteor Atmos Phys 96:203-220. doi:10.1007/s00703-006-0207-6

Simmons A, Uppala S, Dee D, Kobayashi S (2007) Era-interim: new ECMWF reanalysis products from 1989 onwards. ECMWF Newsletter 110:25-35

Singleton AT, Reason CJC (2006) A numerical model study of an intense cutoff low pressure system over South Africa. Mon Wea Rev 135:1128-1150. doi:10.1175/MWR3311.1

Singleton AT, Reason CJC (2007) Variability in the characteristics of cut-off low pressure systems over subtropical Southern Africa. Int J Climatol 27:295-310. doi:10.1002/joc.1399
Taljaard JJ (1985) Cut-off lows in the South African region, South African Weather Bureau. Technical paper 14

Trenberth KE, Mo KC (1985) Blocking in the southern hemisphere. Mon Wea Rev 113:3-21. doi:10.1175/1520-0493(1985)113<0003:BITSH>2.0.CO;2

Uppala SM, Kallberg PW, Simmons AJ, Andrae U, Bechtold VDC, Fiorino M, Gibson JK, Haseler J, Hernandez A, Kelly GA, Li X, Onogi K, Saarinen S, Sokka N, Allan RP, Andersson E, Arpe $\mathrm{K}$, Balmaseda MA, Beljaars ACM, Berg LVD, Bidlot J, Bormann N, Caires S, Chevallier F, Dethof A, Dragosavac M, Fisher M, Fuentes M, Hagemann S, Hólm E, Hoskins BJ, Isaksen L, Janssen PAEM, Jenne R, Mcnally AP, Mahfouf JF, Morcrette JJ, Rayner NA, Saunders RW, Simon P, Sterl A, Trenberth KE, Untch A, Vasiljevic D, Viterbo P, Woollen J (2005) The ERA40 re-analysis. Q J R Meteor Soc 131:2961-3012. doi:10.1256/ qj.04.176

Van Delden AV, Neggers R (2003) A case study of tropopause cyclogenesis. Meteor App 10:197-209. doi:10.1017/ S1350482703002081

Vuille M, Ammann C (1997) Regional snowfall patterns in the high arid Andes. J Clim Change 36:413-423. doi:10.102 3/A:1005330802974

Wang XL, Swail VR, Zwiers FW (2006) Climatology and changes of extratropical cyclone activity: comparison of ERA-40 with NCEP-NCAR reanalysis for 1958-2001. J Clim 19:3145-3166. doi:10.1175/JCLI3781.1

Wernli H, Sprenger M (2007) Identification and era-15 climatology of potential vorticity streamers and cutoffs near the extratropical tropopause. J Atmos Sci 64:1569-1586. doi:10.1175/JAS3912.1 